\title{
Synthesis of New Bisphosphonate and Bisphosphonic Acid Derivatives and Heterocyclic and Dialkylcarbamoyl Oxazolone Derivatives with Anticancer and Antischistosomal Activity
}

\author{
Leila S. Boulos ${ }^{\mathrm{a}}$, Ewies F. Ewies ${ }^{\mathrm{a}}$, and Amin F. M. Fahmy ${ }^{\mathrm{b}}$
}

${ }^{\text {a }}$ Department of Organometallic and Organometalloid Chemistry, National Research Centre,

El-Behoos St., P. O. 12622, Dokki, Cairo, Egypt

${ }^{\mathrm{b}}$ Department of Chemistry, Ain Shams University, Faculty of Science, P. O. 11566, Abbassia, Cairo, Egypt

Reprint requests to L.S. Boulos. E-mail: leilagoubran@yahoo.com

Z. Naturforsch. 2011, 66b, 1056-1068; received June 29, 2011

The reaction of 5(4H)-oxazolones with tetraethyl methanediylbis(phosphonate) afforded new 1,1-bisphosphonate and 1,1-bisphosphonic acid derivatives. Moreover, 5(4H)-oxazolones reacted with Wittig reagents to give the corresponding heterocyclic products. Treatment of 5(4H)-oxazolones with trisdialkylaminophosphanes gave the corresponding $N$-(1-dialkylcarbamoyl)-2-phenylvinylbenzamides. Mechanisms accounting for the formation of the new products are discussed. The biological activity of the newly synthesized compounds was also examined.

Key words: 1,1-Bisphosphonate, 1,1-Bisphosphonic Acid, Wittig Reagents, Oxazolones, Anticancer Activity, Antischistosomal Activity

\section{Introduction}

Bisphosphonates, especially the nitrogen-containing analogs, have been reported to be potent inhibitors of bone resorption and highly selective bone targeting agents [1-3]. Moreover, nitrogen-, sulfur- or oxygencontaining five- and six-membered heterocyclic compounds have enormous significance in the field of medicinal chemistry. Oxazolones play a very vital role in the manufacturing of various biologically active drugs with analgesic [4], anti-inflammatory [5], antidepressant [6], anticancer [7], antimicrobial, antidiabetic, and anti-obesity activity $[8,9]$. In view of this, and in continuation of our work in organophosphorus chemistry [10-16], it was of considerable interest to synthesize new 1,1-bisphosphonate, 1,1-bisphosphonic acid and heterocyclic oxazolone derivatives to obtain potent biologically active compounds.

The present study deals with the reaction of 5(4H)-oxazolones 1a-e with tetraethyl methanediylbis(phosphonate) (2), phosphonium ylides $\mathbf{3 a}-\mathbf{c}$, and trisdialkylaminophosphanes $\mathbf{4 a}-\mathbf{b}$ (Fig. 1).

\section{Results and Discussion}

Chemistry

4-Benzylidene-2-phenyl-5(4H)-oxazolone (1a) was treated with two molar equivalents of tetraethyl methanediylbis(phosphonate) (2) in anhydrous dimethylformamide (DMF) solution using excess $\mathrm{NaH}$ as a base. After the reaction took place, dilute aqueous $\mathrm{HCl}$ was added to the reaction mixture at $-5{ }^{\circ} \mathrm{C}$. The crude<smiles>O=C1OC(c2ccccc2)=N/C1=C/Br</smiles>

$$
\begin{aligned}
\text { 1a, } \mathrm{Ar} & =\mathrm{C}_{6} \mathrm{H}_{5} \\
\text { b, } \mathrm{Ar} & =4-\mathrm{NO}_{2}-\mathrm{C}_{6} \mathrm{H}_{4} \\
\text { c, } \mathrm{Ar} & =4-\mathrm{N}\left(\mathrm{CH}_{3}\right)_{2}-\mathrm{C}_{6} \mathrm{H}_{4} \\
\text { d, } \mathrm{Ar} & =3,4,5-\left(\mathrm{OCH}_{3}\right)_{3}-\mathrm{C}_{6} \mathrm{H}_{2} \\
\text { e, } \mathrm{Ar} & =4-\mathrm{OCH}_{3}-\mathrm{C}_{6} \mathrm{H}_{4}
\end{aligned}
$$

\section{$\left(\mathrm{C}_{6} \mathrm{H}_{5}\right)_{3} \mathrm{P}=\mathrm{CHR}^{1}$}

3a, $\mathrm{R}^{1}=\mathrm{COOCH}_{3}$

b, $\mathrm{R}^{1}=\mathrm{COOC}_{2} \mathrm{H}_{5}$

c, $\mathrm{R}^{1}=\mathrm{CN}$
$: \mathrm{P}\left(\mathrm{NR}^{2}{ }_{2}\right)_{3}$

4a, $\mathrm{R}^{2}=\mathrm{CH}_{3}$

b, $\mathrm{R}^{2}=\mathrm{C}_{2} \mathrm{H}_{5}$

Fig. 1. 


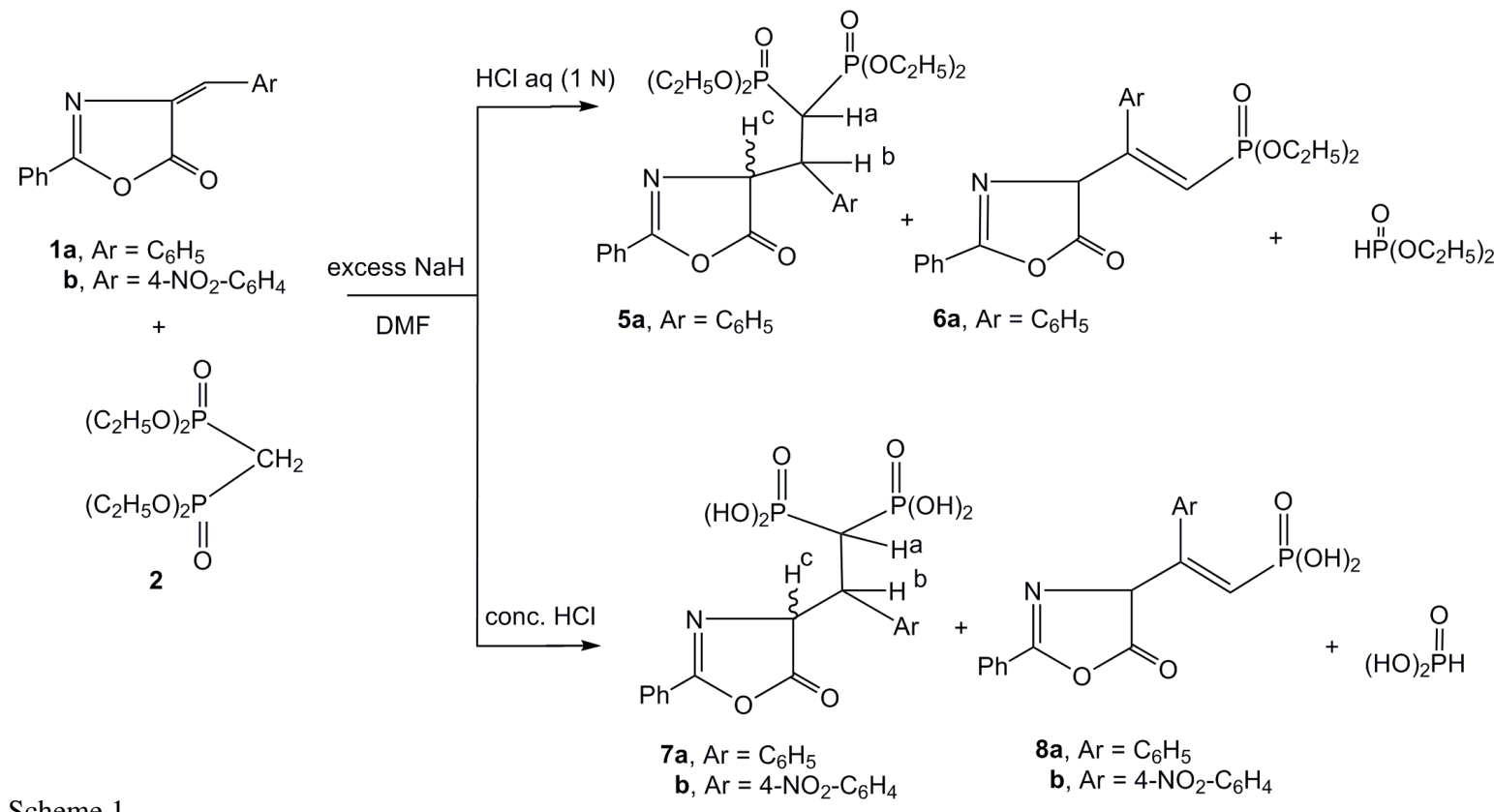

Scheme 1.

$7 \mathrm{a}, \mathrm{Ar}=\mathrm{C}_{6} \mathrm{H}_{5}$

b, $\mathrm{Ar}=4-\mathrm{NO}_{2}-\mathrm{C}_{6} \mathrm{H}_{4}$ 8a, $\mathrm{Ar}=\mathrm{C}_{6} \mathrm{H}_{5}$

b, $\mathrm{Ar}=4-\mathrm{NO}_{2}-\mathrm{C}_{6} \mathrm{H}_{4}$ product was easily separated by solvent extraction and purified by column chromatography to give 1,1-bisphosphonate 5a as the major product (45\% yield) together with the phosphonate adduct 6a. Diethylphosphite was also identified (by TLC) (Scheme 1).

The most important feature of structure $5 \mathbf{a}$ is the presence of two signals at $\delta_{\mathrm{P}}=23.16$ (s) and $25.16 \mathrm{ppm}$ (s) in its ${ }^{31} \mathrm{P}$ NMR spectrum. Moreover, the ${ }^{1} \mathrm{H}$ NMR spectrum of $\mathbf{5 a}(500 \mathrm{MHz})$ revealed three types of methine protons with different chemical shifts at $\delta_{\mathrm{H}}=1.92\left(\mathrm{ddd}, J=7\right.$ and $\left.21.6 \mathrm{~Hz}, 1 \mathrm{H}, \mathrm{CH}-\mathrm{P}_{2}\right)$, $3.45,3.47\left(2 \mathrm{dd}\right.$ each set with $J_{\mathrm{HH}}=7.8 \mathrm{~Hz},{ }^{3} J_{\mathrm{HP}}=$ $\left.12 \mathrm{~Hz}, 1 \mathrm{H}, \mathrm{CHCH}-\mathrm{P}_{2}\right)$ and $4.38 \mathrm{ppm}(\mathrm{dd}, J=7$ and $6 \mathrm{~Hz}, 1 \mathrm{H}$, cyclic $\mathrm{CH})$. Also, ${ }^{13} \mathrm{C}$ NMR spectroscopy confirmed that both phosphorus atoms are attached to the same quaternary carbon atom $\left[\delta_{\mathrm{C}}=25.3\left(\mathrm{dd}, J_{\mathrm{CP}}=\right.\right.$ 130 and $\left.132 \mathrm{~Hz}, \mathrm{C}-\mathrm{P}_{2}\right)$ ]. The structure of $\mathbf{5 a}$ has also been assigned on the basis of elemental analysis and mass spectral data ( $c f$. Experimental Section). Compound 6a (minor product, $25 \%$ yield) was identified as diethyl 2-(4,5-dihydro-5-oxo-2-phenyloxazol-4-yl)2-phenylvinylphosphonate on the basis of its IR, ${ }^{1} \mathrm{H}$, ${ }^{13} \mathrm{C},{ }^{31} \mathrm{P}$ NMR and mass spectral data ( $c f$. Experimental Section).

On the other hand, performing the reaction of $\mathbf{1 a}$ with 2 in concentrated hydrochloric acid instead of dilute acid led to the formation of bisphosphonic acid 7a as the main product (55\% yield), vinylphosphonic acid $8 \mathbf{a}$ ( $25 \%$ yield) and phosphorus acid (Scheme 1). The structural assignments for compounds 7a and 8a are based upon elemental and spectroscopic data (IR, ${ }^{1} \mathrm{H},{ }^{13} \mathrm{C},{ }^{31} \mathrm{P}$ NMR and mass spectra) (cf. Experimental Section).

Similarly, when 1,3-oxazol-5(4H)-one 1b was reacted with bis(phosphonate) 2 using concentrated hydrochloric acid, bisphosphonic acid $\mathbf{7 b}$ (the major product) and phosphonic acid $\mathbf{8 b}$ were obtained. Phosphorus acid was also identified (TLC) in the reaction medium (Scheme 1). Structure elucidation of $\mathbf{7 b}$ and $\mathbf{8 b}$ was derived from their spectral data ( $c f$. Experimental Section).

A possible explanation for the course of the reaction of $1 \mathbf{a}$ and $\mathbf{1 b}$ with $\mathbf{2}$ is shown in Scheme 1. 1,1-bisphosphonate $\mathbf{5 a}$ is possibly formed through a Michael addition [3,17] of $\mathbf{2}$ to oxazolone 1a. Moreover, the phosphonate adduct $\mathbf{6 a}$ can result from a simple acid catalyzed elimination of diethyl phosphite from $\mathbf{5 a}$ (Scheme 1).

On the other hand, the substituted 1,1-bisphosphonic acids $7 \mathbf{a}, \mathbf{b}$ and vinylphosphonic acids $\mathbf{8 a}, \mathbf{b}$ were easily obtained via acid hydrolysis with concentrated $\mathrm{HCl}$, which enabled the phosphonate ester to be removed to give directly $7 \mathbf{a}, \mathbf{b}$ and $\mathbf{8 a}, \mathbf{b}$, respectively, with elimination of phosphorous acid (Scheme 1). Previous work has reported the synthesis of substituted 1,1-bisphosphonic acid through hydrolysis of the cor- 


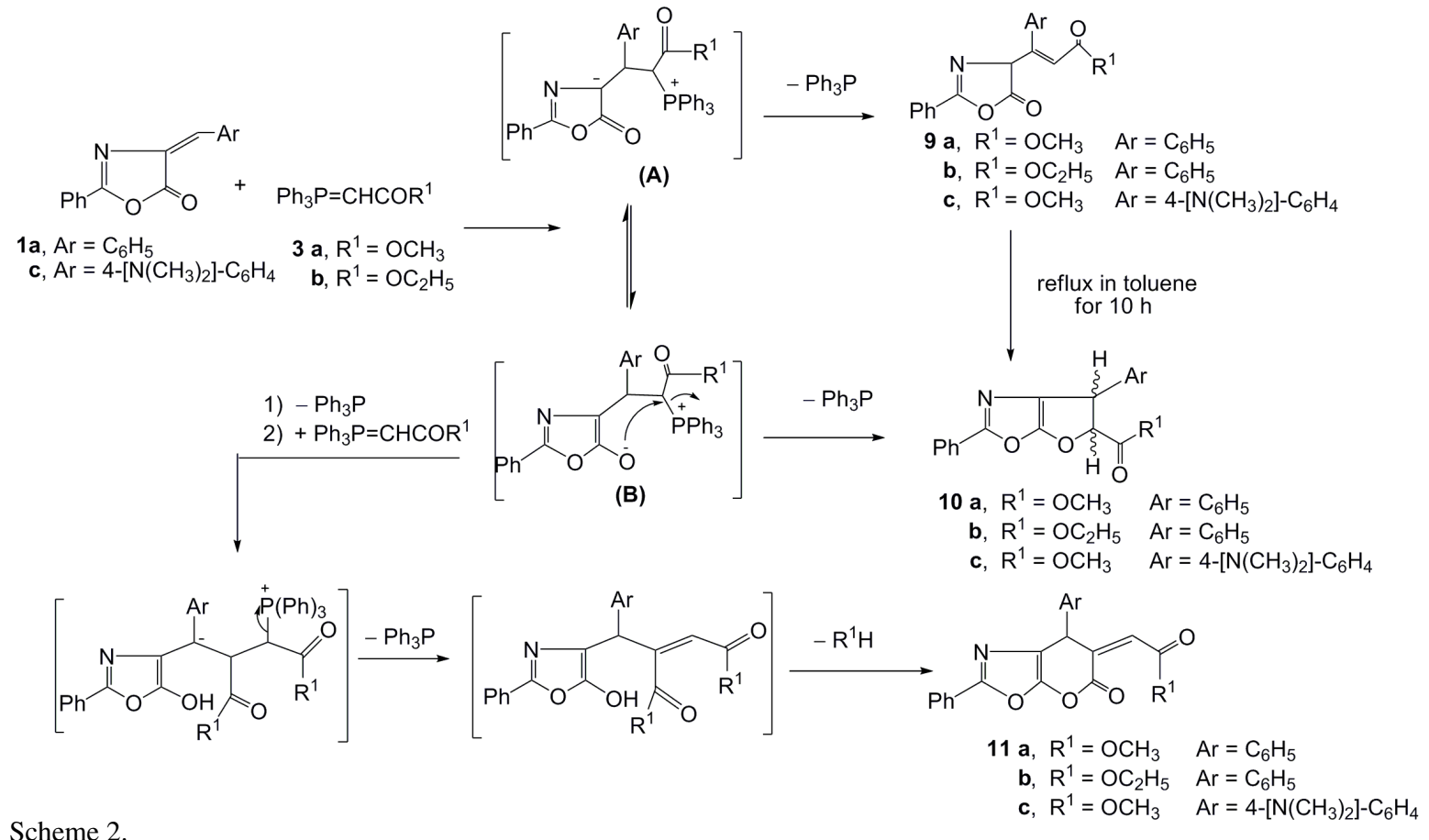

Scheme 2.

responding bisphosphonate product with concentrated hydrochloric acid [18]. The present study showed that substituted 1,1-bisphosphonic acids can be synthesized directly from the reaction of 4-arylidene-2-phenyl-5(4H)-oxazolone derivatives 1a, b with bisphosphonate 2 using concentrated hydrochloric acid ( $c f$. Experimental Section).

Worthy to mention is that only one isomer of bisphosphonate $\mathbf{5 a}$ and the bisphosphonic acids $\mathbf{7 a}, \mathbf{b}$ was isolated, suggested as syn configuration. The assigned syn configuration for these products, although not established with certainly, is supported by an inspection of a model drawn by Newman projection as well as by the chemical shifts and coupling constants of the exocyclic methine protons, and especially $\mathrm{CH}^{\mathrm{b}}-\mathrm{CH}^{\mathrm{a}}-\mathrm{P}$, in their ${ }^{1} \mathrm{H}$ NMR spectra. The observed coupling constants of $\mathrm{H}^{\mathrm{b}}\left(J_{\mathrm{H}^{\mathrm{b}} \mathrm{H}^{\mathrm{a}}}=J_{\mathrm{H}^{\mathrm{b}} \mathrm{H}^{\mathrm{c}}}, c a .6-8 \mathrm{~Hz}\right)$ indicate the syn form, rather than the anti configuration which would give rise to larger coupling constants $(9-15 \mathrm{~Hz})$.

Furthermore, this study was extended to include the behavior of oxazolones $\mathbf{1}$ towards phosphonium ylides $3 \mathbf{a}-\mathbf{c}$ and tris(dialkylamino)phosphanes $\mathbf{4 a}, \mathbf{b}$ to determine the preferential site of attack. We have found that when oxazolone 1a was allowed to react with two molar equivalents of ylides $\mathbf{3 a}$ and $\mathbf{3 b}$ in re- fluxing toluene, products $9 \mathbf{a}, \mathbf{b}, \mathbf{1 0 a}, \mathbf{b}, \mathbf{1 1 a}, \mathbf{b}$, triphenylphosphane, and unchanged oxazolone 1a were isolated. Carrying out the reaction using three instead of two molar equivalents of phosphonium ylides $\mathbf{3 a}, \mathbf{b}$ under the same reaction conditions led to the formation of compounds $9 \mathbf{a}, \mathbf{b}, \mathbf{1 0 a}, \mathbf{b}, \mathbf{1 1 a}, \mathbf{b}$ in good yields. Triphenylphosphane was also isolated in each case (Scheme 2).

Similarly, oxazolone 1c reacted with three molar equivalents of 3a, to give products $9 \mathbf{c}, 10 \mathbf{c}$ and 11c, respectively. Triphenylphosphane was also isolated (Scheme 2). Compounds 9a-c, 10a-c and 11a-c were obtained chromatographically pure by silica gel column chromatography and possess sharp melting points. Their structures were assigned based on elemental analysis, IR, ${ }^{1} \mathrm{H},{ }^{13} \mathrm{C}$ NMR and mass spectral data ( $c f$. Experimental Section).

A possible explanation for the course of the reaction of 1a and 1c with the Wittig reagents 3a, b is shown in Scheme 2. Formation of products $9 \mathbf{a}-\mathbf{c}$ presumably occurs via Michael addition of the ylide species $\mathbf{3 a}, \mathbf{b}$ to the active methine carbon atom in oxazolones $\mathbf{1 a}$ and $\mathbf{1 c}$ to afford the intermediate $\mathbf{A}$. Since triphenylphosphane is a good leaving group [19,20], Hofmann elimination [21] of triphenylphosphane followed by proton transfer leads to the final prod- 
<smiles>[R]C=C([Al])C1N=C(c2ccccc2)OC1=O</smiles><smiles>[R]C1Oc2oc(-c3ccccc3)nc2[C@H]1Br</smiles>

9d, $\mathrm{R}^{1}=\mathrm{COOC}_{2} \mathrm{H}_{5}, \mathrm{Ar}=4-\mathrm{NO}_{2}-\mathrm{C}_{6} \mathrm{H}_{4}$ $\uparrow$

10d, $\mathrm{R}^{1}=\mathrm{COOC}_{2} \mathrm{H}_{5}, \mathrm{Ar}=4-\mathrm{NO}_{2}-\mathrm{C}_{6} \mathrm{H}_{4}$
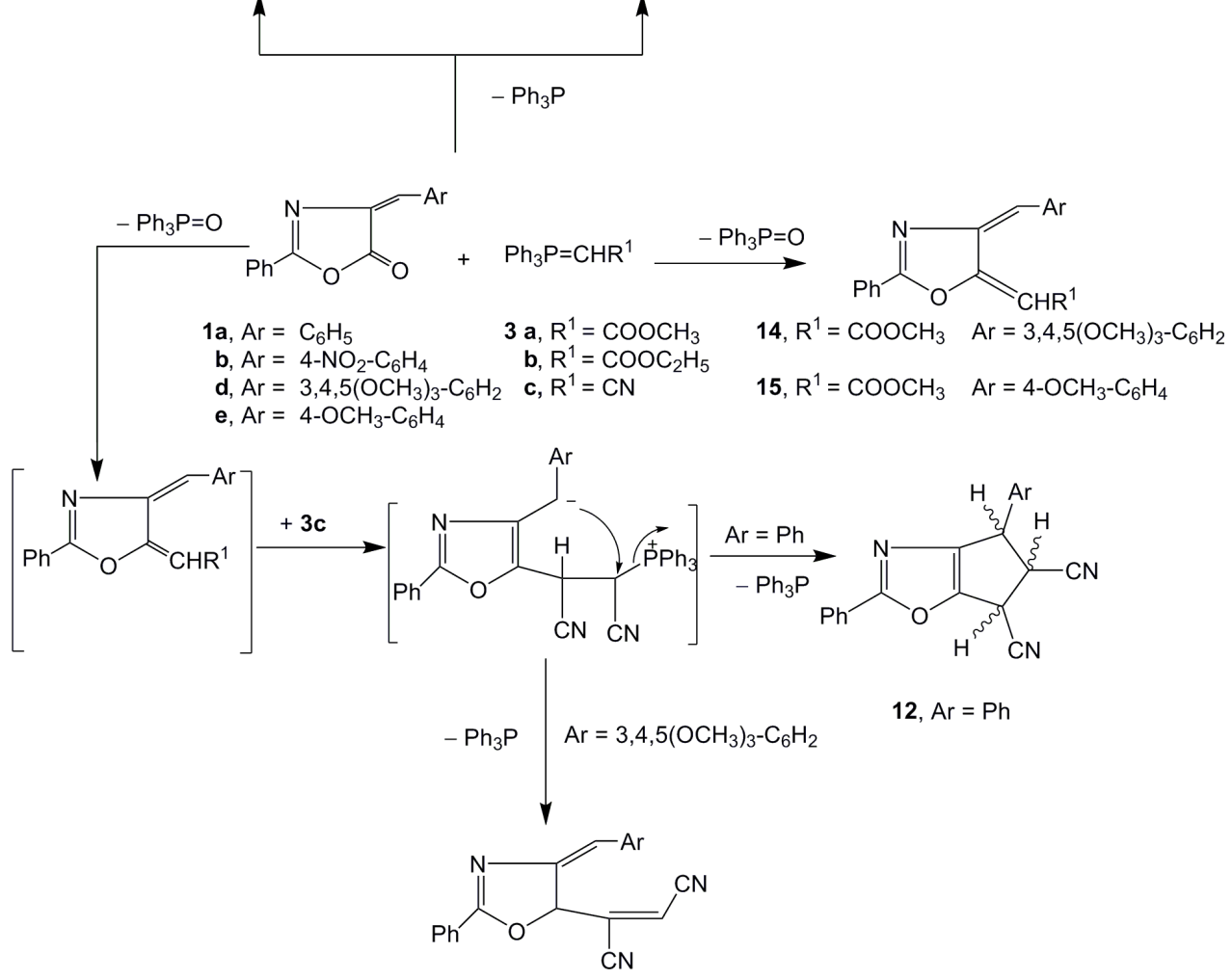

13, $\mathrm{Ar}=3,4,5\left(\mathrm{OCH}_{3}\right)_{3}-\mathrm{C}_{6} \mathrm{H}_{2}$

Scheme 3 .

ucts $9 \mathbf{a}-\mathbf{c}$. Moreover, compounds $10 \mathbf{a}-\mathbf{c}$ can be obtained by protonation of $\mathbf{1 a}, \mathbf{c}$ at the carbanion center of ylides $\mathbf{3 a}, \mathbf{b}$ to give the transient intermediate (B) followed by elimination of triphenylphosphane to afford $\mathbf{1 0 a}-\mathbf{c}$. It is worthy to mention that when compounds $9 \mathbf{a}-\mathbf{c}$ were heated in toluene for $10 \mathrm{~h}$, the bicyclic compounds $\mathbf{1 0 a}-\mathbf{c}$ were obtained in $85 \%$ yield. Compounds $\mathbf{1 1 a}-\mathbf{c}$ may be regarded as products of an intramolecular Wittig reaction. Such addition-cyclization products apparently result from the addition of another ylide molecule $\mathbf{3 a}, \mathbf{b}$ to the intermediate $\mathbf{B}$ followed by elimination of triphenylphosphane and the appropriate alcohol molecule under the applied reaction conditions to give the cyclic products 11a-c (Scheme 2).

Next, when oxazolone $\mathbf{1 b}$ was allowed to react with two molar equivalents of $\mathbf{3 b}$, products $9 \mathbf{d}$ and $\mathbf{1 0 d}$ were obtained in good yield. Triphenylphosphane was also isolated and identified (Scheme 3). Moreover, when $1 \mathbf{a}$ and $1 \mathbf{d}$ were allowed to react with two molar equivalents of (triphenyl- $\lambda^{5}$-phosphanylidene)acetonitrile (3c) in refluxing toluene, bicyclic dicarbonitrile 12, and 2-[2-phenyl-4-but-2-enedinitrile 13 were obtained. Triphenylphosphane and triphenylphosphane oxide were also isolated from the reaction mixture (Scheme 3). The structures of 9d, 10d, 12, and 13 have been confirmed on the basis of the full set of their spectral data ( $c f$. Experimental Section). Also, when compound 1d reacted with one molar equivalent of $\mathbf{3 a}$ in refluxing toluene, methyl oxazol-5(4H)-ylidene)acetate 14 was obtained in $85 \%$ yield. Triphenylphosphane oxide was also isolated.

Similarly, oxazolone 1e reacted with one molar equivalent of $\mathbf{3 a}$ in refluxing toluene, to give methyl 

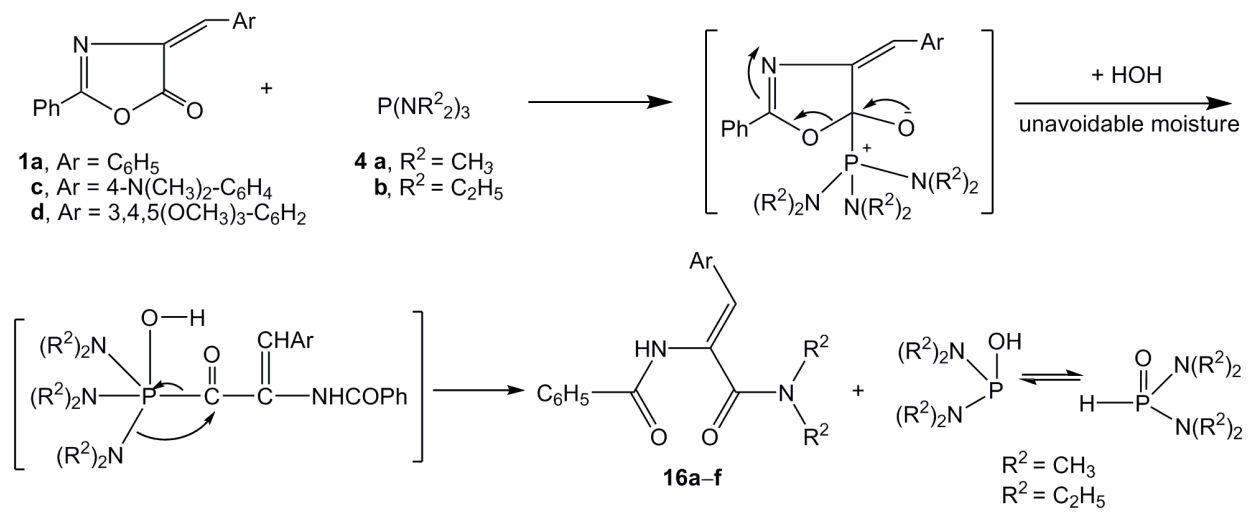

Scheme 4 .

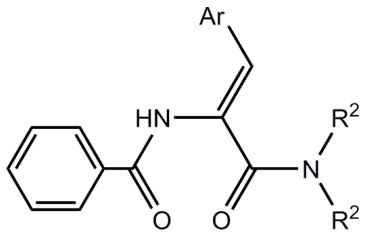

$$
\begin{aligned}
& \text { 16a, } \mathrm{Ar}=\mathrm{C}_{6} \mathrm{H}_{5} \\
& \text { b, } \mathrm{Ar}=\mathrm{C}_{6} \mathrm{H}_{5} \\
& \text { c, } \mathrm{Ar}=4-\mathrm{N}\left(\mathrm{CH}_{3}\right)_{2}-\mathrm{C}_{6} \mathrm{H}_{4} \quad \mathrm{R}^{2}=\mathrm{CH}_{3} \\
& \text { d, } \mathrm{Ar}=4-\mathrm{N}\left(\mathrm{CH}_{3}\right)_{2}-\mathrm{C}_{6} \mathrm{H}_{4} \quad \mathrm{R}^{2}=\mathrm{C}_{2} \mathrm{H}_{5} \\
& \text { e, } \mathrm{Ar}=3,4,5\left(\mathrm{OCH}_{3}\right)_{3}-\mathrm{C}_{6} \mathrm{H}_{2} \quad \mathrm{R}^{2}=\mathrm{CH}_{3} \\
& \text { f, } \mathrm{Ar}=3,4,5\left(\mathrm{OCH}_{3}\right)_{3}-\mathrm{C}_{6} \mathrm{H}_{2} \quad \mathrm{R}^{2}=\mathrm{C}_{2} \mathrm{H}_{5}
\end{aligned}
$$

Fig. 2.

oxazol-5(4H)-ylidene)acetate 15 in $82 \%$ yield besides triphenylphosphane oxide (Scheme 3). The structure elucidation of compounds 14 and 15 was based on their analytical and spectral data ( $c f$. Experimental Section).

The reactions of 4-arylidene-2-phenyl-5(4H)-oxazolones 1a, c, $\mathbf{d}$ with tris(dialkylamino)phosphanes $4 \mathbf{a}$ and $\mathbf{4 b}$ were also investigated. We have found that the reaction of $\mathbf{1 a}, \mathbf{c}, \mathbf{d}$ with one molar equivalent of each $\mathbf{1}$ and $\mathbf{4}$ in dry dichloromethane at r.t., affords the pure adducts formulated as $\mathbf{1 6} \mathbf{a}-\mathbf{f}$ (Fig. 2).

Products $16 \mathbf{a}-\mathbf{f}$ were presumably formed via nucleophilic attack of $\mathbf{4 a}, \mathbf{b}$ on the lactone carbonyl group in 1a, $\mathbf{c}, \mathbf{d}$ followed by azalactone ring opening. Since dialkylaminophosphite is a good leaving group, compounds $16 \mathbf{a}-\mathbf{f}$ can be formed through rapid hydrolysis due to the presence of unavoidable moisture (Scheme 4). The structures of compounds $16 \mathbf{a}-\mathbf{f}$ were attested by their elemental analysis, IR, ${ }^{1} \mathrm{H},{ }^{13} \mathrm{C}$ NMR and mass spectral data ( $c f$. Experimental Section).

It is worth mentioning that when $5(4 H)$-oxazolones $\mathbf{1 a}, \mathbf{c}, \mathbf{d}$ were allowed to react with a secondary amine, the same compounds $\mathbf{1 6} \mathbf{a}-\mathbf{f}$ were obtained in good yields ( $c f$. Experimental Section).
Table 1. Effect of the tested compounds on MCF7 tumor cell lines (breast cancer).

\begin{tabular}{ll}
\hline Compound & $\mathrm{IC}_{50}\left(\mu \mathrm{g} \mathrm{mL}^{-1}\right)$ \\
\hline Doxorubicin (st.) & 2.97 \\
9a & 21.1 \\
9b & 21.4 \\
$\mathbf{1 0 c}$ & 19.3 \\
$\mathbf{1 2}$ & 19.3 \\
$\mathbf{1 3}$ & 19.6 \\
\hline
\end{tabular}

\section{Pharmacological evaluation}

Cancer diseases are a serious threat to health and development of mankind, and the search for effective anti-cancer agents is a continuing challenge. Considerable progress has been made in recent years in the field of drug development against different types of cancer. Chemotherapy is a major approach for both localized and metastasized cancers [22], and for many years oxazolone-related compounds have proved to have significant therapeutic potential [23]. Based on these considerations, five of the newly synthesized compounds were screened for their in vitro cytotoxic and growth inhibitory activities against human breast carcinoma cell line (MCF7), in comparison with the activity of the anticancer agent Doxorubicin (DXR) as a reference drug. The cytotoxic activities of the tested compounds were expressed as the median growth inhibitory concentration $\left(\mathrm{IC}_{50}\right)$ which is the dose that reduces survival to $50 \%$. The screening results are compiled in Table 1. According to the American National Cancer Institute guidelines [24], drugs with $\mathrm{IC}_{50}<30 \mu \mathrm{g} \mathrm{mL}^{-1}$ are active. From Table 1, it is evident that most of the tested compounds show anti-tumor activities with $\mathrm{IC}_{50}$ values ranging from $19.3-21.4 \mu \mathrm{g} \mathrm{mL}^{-1}$.

The comparison of the cytotoxicity against MCF7 cells (Fig. 3) of the prepared compounds shows that the cell killing potency follows the order $10 c=12>$ 
Table 2. In vitro evaluation of compounds for schistosomicidal activity at $10 \mu \mathrm{g} \mathrm{mL}^{-1}$.

\begin{tabular}{|c|c|c|c|c|c|c|c|c|}
\hline \multirow[t]{3}{*}{ Formula numbers } & \multirow{2}{*}{\multicolumn{2}{|c|}{$1^{\text {st }}$ day }} & \multicolumn{2}{|r|}{$2^{\text {nd }}$ day } & \multirow{2}{*}{\multicolumn{2}{|c|}{$3^{\text {rd }}$ day }} & \multicolumn{2}{|r|}{$4^{\text {th }}$ day } \\
\hline & & & \multicolumn{3}{|c|}{ No. of worms (12) } & & \multirow[b]{2}{*}{ Dead } & \multirow[b]{2}{*}{ Mortality (\%) } \\
\hline & Dead & Mortality (\%) & Dead & Mortality (\%) & Dead & Mortality (\%) & & \\
\hline$\overline{16 a}$ & 0 & 0 & 0 & 0 & 0 & 0 & 2 & 16.7 \\
\hline $16 b$ & 0 & 0 & 0 & 0 & 1 & 8.3 & 5 & 41.7 \\
\hline $16 \mathrm{c}$ & 0 & 0 & 0 & 0 & 0 & 0 & 4 & 33.3 \\
\hline 16d & 0 & 0 & 0 & 0 & 2 & 16.7 & 2 & 16.7 \\
\hline $16 e$ & 0 & 0 & 0 & 0 & 7 & 58.3 & 12 & 100 \\
\hline $16 f$ & 0 & 0 & 0 & 0 & 0 & 0 & 4 & 33.3 \\
\hline PZQ (+ve) Control ${ }^{\mathrm{a}}$ & 12 & 100 & 12 & 100 & 12 & 100 & 12 & 100 \\
\hline DMSO (-ve) Control & 0 & 0 & 0 & 0 & 0 & 0 & 0 & 0 \\
\hline
\end{tabular}

${ }^{a}$ Praziquantel (PZQ) is the mainstay of schistosomiasis control programs worldwide.

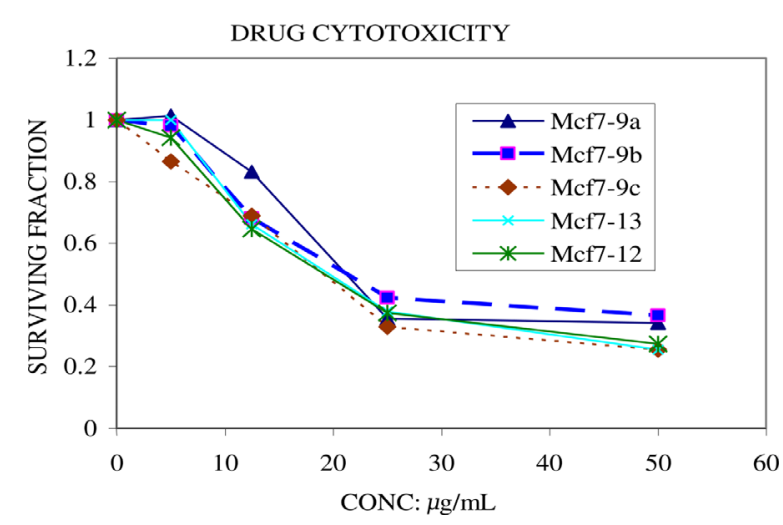

Fig 3. Effect of the tested compounds on MCF7 tumor cell lines.

$13>9 \mathbf{a}>9 \mathbf{b}$. This may be attributable to the presence of the oxazolone moiety by contributing to the cytotoxic activity through interaction with DNA by intercalation and inhibition of the macromolecular biosynthesis. This inhibits the progression of the enzyme transcription topoisomerase II, which unwinds DNA for transcription and stabilizes the topoisomerase II complex after it has broken the DNA chain for replication, preventing the DNA double helix from being resealed. This process stops the replication in the same way as the Doxorubicin [25] suppressing agent, thus inhibiting the formation and growth of tumors from initiated cells [26].

\section{Antischistosomal activity of some compounds}

It is well known that organophosphorus compounds are the most important group of pesticides due to their rapid metabolism [27]. On the other hand, oxazolone derivatives serve a wide range of pharmaceutical and biological purposes [28], and they also possess insecticidal effects [29]. Therefore, this work aimed to prepare some oxazolone derivatives and to test
Table 3. In vitro antischistosomal effect $\left(\mathrm{IC}_{50}\right.$ and $\left.\mathrm{IC}_{90}\right)$ of compound 16e compared to PZQ.

\begin{tabular}{lll}
\hline Compound & $\mathrm{IC}_{50}\left(\mu \mathrm{g} \mathrm{mL}^{-1}\right)$ & $\mathrm{IC}_{90}\left(\mu \mathrm{g} \mathrm{mL}^{-1}\right)$ \\
\hline 16e & 7.04 & 9.01 \\
PZQ $(+v e)$ control & 0.4 & 0.64 \\
\hline
\end{tabular}

them for antischistosomal activity in vitro on Schistosoma mansoni worms. The results revealed that benzamide 16e possesses in vitro antischistosomal activity ( $100 \%$ mortality). Compounds $\mathbf{1 6 a}-\mathbf{d}$ and $\mathbf{1 6 f}$ showed various degrees of lethal efficacy rang (17-42\% mortality) on worms at $10 \mu \mathrm{g} \mathrm{mL}^{-1}$ after $4 \mathrm{~d}$ of exposure (Table 2).

Compound 16e was further subjected to the determination of its $\mathrm{IC}_{50}$ and $\mathrm{IC}_{90}$ values (Table 3 ). The results have shown that compound $\mathbf{1 6 e}$ possesses the strongest antischistosomal activity ( $\mathrm{IC}_{50}$ values equal to or less than $10 \mu \mathrm{g} \mathrm{mL}^{-1}$ ).

\section{Conclusion}

Based on the results of the present investigations, it could be concluded that tetraethyl methanediylbis(phosphonate) (2), phosphonium ylides and tris(dialkylamino)phosphanes behave differently towards 2-aryl-5(4H)-oxazolones 1 . While the reaction of 2 with oxazolones $\mathbf{1 a}, \mathbf{b}$ resulted in the formation of the new 1,1-bisphosphonate, 1,1-bisphosphonic acid, and phosphonate derivatives, a different course was observed in the reaction of $\mathbf{1}$ with stabilized ylides $\mathbf{3}$ and tris(dialkylamino)phosphanes 4 , depending on the nature of the addition products. A simple and direct method for the synthesis of substituted 1,1-bisphosphonic acids is also reported.

Some of the newly synthesized compounds were screened for their anticancer and antischistosomal activities. The compounds 9a, 9b, 10c, 12, and 13 revealed pronounced in vitro antitumor activities when 
tested against human breast cancer carcinoma cell lines (MCF7) in comparison with the anticancer agent Doxorubicin (DXR) as a reference. The most promising result against breast carcinoma (MCF7) was obtained by oxazoledicarbonitrile 12, oxazolemaleonitrile 13, and oxazole dicarboxylate 10c. They showed antitumor activities ranging from $19.3-19.6 \mu \mathrm{g} \mathrm{mL}^{-1}$. On the other hand, the antischistosomal activity of the compounds $\mathbf{1 6 a}-\mathbf{d}, \mathbf{1 6} \mathbf{f}$ showed that $N$-((1-dimethylcarbamoyl)-2-(3,4,5-trimethoxyphenyl)vinyl) benzamide 16e possesses in vitro antischistosomal activity (mortality $100 \%, \mathrm{IC}_{50}$ values equal to or less than $10 \mu \mathrm{g} \mathrm{mL}^{-1}$ ). Compound 16e therefore is considered a promising bioactive compound which deserves further investigation.

Notably, clinical trials showed that high activity is observed for methylene-bisphosphonates with nitrogen-containing heteroaromatic substituents. Data on pharmacological potency of the new bisphosphonate will be published elsewhere.

\section{Experimental Section}

Melting points were determined in open glass capillaries using an Electrothermal IA 9100 series digital melting point apparatus (Electrothermal, Essex, UK), and IR spectra were measured from $\mathrm{KBr}$ pellets with a Perkin-Elmer Infracord spectrophotometer model 157 . The ${ }^{1} \mathrm{H}$ and ${ }^{13} \mathrm{C}$ NMR spectra were recorded in $\mathrm{CDCl}_{3}$ or $\left[\mathrm{D}_{6}\right] \mathrm{DMSO}$ as solvent on a Jeol $500 \mathrm{MHz}$ spectrometer, and the chemical shifts were recorded in $\delta$ values (ppm) relative to TMS as internal reference. The ${ }^{31} \mathrm{P}$ NMR spectra were taken on a Varian CFT-20 spectrometer in $\delta$ values (ppm) vs. external $85 \% \mathrm{H}_{3} \mathrm{PO}_{4}$ as a standard. The mass spectra were performed at $70 \mathrm{eV}$ on a Shimada GCS-OP 1000 Ex Spectrometer equipped with a data system. Elemental analyses were performed using an Elementar Vario E1 instrument. The values agreed favorably with calculated ones.

General procedure for reactions of 4-arylidene-2-phenyl$5(4 H)$-oxazolone $(\mathbf{l a}, \mathbf{1 b})$ with tetraethyl methanediylbis(phosphonate) (2)

$0.30 \mathrm{~g}(10 \mathrm{mmol}) 80 \%$ sodium hydride in $15 \mathrm{~mL}$ of anhydrous DMF was added slowly to a stirred solution of $\mathbf{2}$ $(1.40 \mathrm{~g}, 5 \mathrm{mmol})$ in anhydrous DMF at $0{ }^{\circ} \mathrm{C}$. After the addition was completed $(1 \mathrm{~h})$, a solution of $\mathbf{1 a}$ or $\mathbf{1 b}(2.5 \mathrm{mmol})$ in anhydrous DMF (10 $\mathrm{mL}$ ) was added, and the resulting mixture was allowed to warm to room temperature and stirred for additional $0.5-5 \mathrm{~h}$ (TLC), and then cooled again to $-5{ }^{\circ} \mathrm{C}$. $\mathrm{HCl}(1 \mathrm{~N})$ was added until $\mathrm{pH}$ was acidic; the mixture was extracted with $\mathrm{CHCl}_{3}(3 \times 50 \mathrm{~mL})$. The combined organic phase was dried over anhydrous $\mathrm{Na}_{2} \mathrm{SO}_{4}$. After removal of the solvent under vacuum, the residue was chromatographed to give the products 5a and 6a. Also diethyl phosphite was identified (TLC).

Carrying out this reaction under the same conditions except adding conc. $\mathrm{HCl}$ instead of $\mathrm{HCl}(1 \mathrm{~N}), \mathbf{7 a}, \mathbf{b}$ as the major products and $\mathbf{8 a}, \mathbf{b}$ were separated. Also phosphorous acid was identified (TLC).

Tetraethyl [2-(5-oxo-2-phenyl-4,5-dihydro-1,3-oxazol-4-yl)2-phenylethane-1,1-diyl]bisphosphonate (5a)

Eluent: petroleum ether-acetone (80/20, v/v). Product 5a was separated as yellow crystals, yield $45 \%$. M. p. $242{ }^{\circ} \mathrm{C}$. $-\mathrm{IR}(\mathrm{KBr}): v=1690(\mathrm{C}=\mathrm{O}), 1635(\mathrm{C}=\mathrm{N})$, $1210(\mathrm{P}=\mathrm{O}), 1120(\mathrm{P}-\mathrm{O}) \mathrm{cm}^{-1} .-{ }^{1} \mathrm{H}$ NMR $(500.14 \mathrm{MHz}$, $\left.\mathrm{CDCl}_{3}\right): \delta=1.34,1.36,1.39,1.41(12 \mathrm{H}, 4 \mathrm{t}, J=7.0 \mathrm{~Hz}$, $\left.4 \mathrm{CH}_{3} \mathrm{CH}_{2} \mathrm{O}\right), 1.90\left(1 \mathrm{H}\right.$, ddd, $\left.J=7.0,21.6 \mathrm{~Hz}, \mathrm{CH}-\mathrm{P}_{2}\right)$, $3.45,3.47\left(1 \mathrm{H}, 2\right.$ dd each set with $J_{\mathrm{HH}}=7.8 \mathrm{~Hz},{ }^{3} J_{\mathrm{HP}}=$ $12 \mathrm{~Hz}, \mathrm{CH}-\mathrm{CH}-\mathrm{P}), 4.1-4.25\left(8 \mathrm{H}, \mathrm{m}, \mathrm{br}, 4 \mathrm{CH}_{2} \mathrm{CH}_{3}\right), 4.40$ $\left(1 \mathrm{H}, \mathrm{dd}, J_{\mathrm{HH}}=7.0,6.0 \mathrm{~Hz}\right.$, cyclic $\left.\mathrm{CH}\right), 7.1-7.9(\mathrm{~m}, 10 \mathrm{H}$, $\left.\mathrm{H}_{\text {arom }}\right) .-{ }^{13} \mathrm{C} \mathrm{NMR}\left(125.76 \mathrm{MHz}, \mathrm{CDCl}_{3}\right): \delta=14.7-$ $15.2,16.3\left(3 \mathrm{~s}, 4 \mathrm{CH}_{2} \mathrm{CH}_{3}\right), 18.7\left(\mathrm{t},{ }^{2} J_{\mathrm{CP}}=8.4 \mathrm{~Hz}, \mathrm{CH}-\right.$ $\mathrm{CH}-\mathrm{P}), 25.3\left(\mathrm{dd}, J_{\mathrm{CP}}=130,132 \mathrm{~Hz}, \mathrm{C}-\mathrm{P}_{2}\right), 62.3,62.4$, 62.6, $62.8\left(4 \mathrm{~s}, 4 \mathrm{CH}_{2} \mathrm{O}\right.$ ), 71.8 (cyclic $\mathrm{CH}$ ), 126.2 - 148.6 (aromatic $\mathrm{C}-\mathrm{H})), 154.8(\mathrm{C}=\mathrm{N}), 165.6(\mathrm{C}=\mathrm{O}) .-{ }^{31} \mathrm{P}$ NMR: $\delta=$ 23.16, 25.16. - MS (EI, $70 \mathrm{eV}): m / z(\%)=537$ (20) [M$1]^{+}, 536(25)[\mathrm{M}-2]^{+}, 535(12)[\mathrm{M}-3]^{+}, 401(55)[\mathrm{M}-$ 137, $\left(\mathrm{P}(\mathrm{O})\left(\mathrm{OC}_{2} \mathrm{H}_{5}\right)_{2}\right]^{+}$. $-\mathrm{C}_{25} \mathrm{H}_{33} \mathrm{NO}_{8} \mathrm{P}_{2}$ (537.17): calcd. C 55.87, H 6.19, N 2.61, P 11.53; found C 55.66, H 6.18, $\mathrm{N} 2.82, \mathrm{P} 11.23$.

Diethyl [2-(4,5-dihydro-5-oxo-2-phenyloxazol-4-yl)-2-phenylvinyl]phosphonate $(\mathbf{6} \boldsymbol{a})$

Eluent: petroleum ether-acetone $(95 / 5, \mathrm{v} / \mathrm{v})$. Product $6 \mathrm{a}$ was separated as pale-yellow crystals, yield $25 \%$. M. p. $145-146^{\circ} \mathrm{C} .-\mathrm{IR}(\mathrm{KBr}): v=1690(\mathrm{C}=\mathrm{O}), 1640(\mathrm{C}=\mathrm{N})$, $1610(\mathrm{C}=\mathrm{C}), 1237(\mathrm{P}=\mathrm{O}), 1127(\mathrm{P}-\mathrm{O}) \mathrm{cm}^{-1} \cdot-{ }^{1} \mathrm{H}$ NMR $\left(500.14 \mathrm{MHz}, \mathrm{CDCl}_{3}\right): \delta=1.35,1.37(6 \mathrm{H}, 2 \mathrm{dt}, J=6.7$, $\left.4.9 \mathrm{~Hz}, 2 \mathrm{CH}_{3} \mathrm{CH}_{2} \mathrm{O}\right), 4.0(1 \mathrm{H}, \mathrm{s}$, cyclic $\mathrm{CH}), 4.30,4.35(4 \mathrm{H}$, $\left.2 \mathrm{q},{ }^{3} J_{\mathrm{HP}}=11.7 \mathrm{~Hz}, 2 \mathrm{CH}_{3} \mathrm{CH}_{2}-\mathrm{O}-\mathrm{P}\right), 5.3\left(1 \mathrm{H}, \mathrm{d},{ }^{2} J_{\mathrm{HP}}=\right.$ $18.6 \mathrm{~Hz}, \mathrm{CH}-\mathrm{P}), 7.2-7.8\left(\mathrm{~m}, 10 \mathrm{H}, \mathrm{H}_{\text {arom }}\right) .-{ }^{13} \mathrm{C} \mathrm{NMR}$ $\left(125.76 \mathrm{MHz}, \mathrm{CDCl}_{3}\right): \delta=14.90,15.30\left(2 \mathrm{CH}_{3} \mathrm{CH}_{2} \mathrm{O}\right)$, 62.10, $62.70\left(2 \mathrm{~d},{ }^{2} J_{\mathrm{CP}}=28.25 \mathrm{~Hz}, \mathrm{CH}_{3} \mathrm{CH}_{2}-\mathrm{O}-\mathrm{P}\right), 75.8$ (cyclic $\mathrm{CH}), 103.8\left(\mathrm{~d}, J_{\mathrm{CP}}=93.2 \mathrm{~Hz}, \mathrm{C}-\mathrm{P}\right), 126.4-139.4$ (aromatic C-H), $154.2(\mathrm{C}=\mathrm{N}), 165.2(\mathrm{C}=\mathrm{O}) .-{ }^{31} \mathrm{P} \mathrm{NMR}: \delta=$ 20.34. - MS (EI, $70 \mathrm{eV}): \mathrm{m} / \mathrm{z}(\%)=399(15)[\mathrm{M}]^{+}, 262(100)$ $\left[\mathrm{M}-137,\left(\mathrm{P}(\mathrm{O})\left(\mathrm{OC}_{2} \mathrm{H}_{5}\right)_{2}\right]^{+} .-\mathrm{C}_{21} \mathrm{H}_{22} \mathrm{NO}_{5} \mathrm{P}\right.$ (399.12): calcd. C 63.15, H 5.55, N 3.51, P 7.76; found C 63.20, H 5.42, N 3.72, P 8.02.

[2-(5-Oxo-2-phenyl-4,5-dihydro-1,3-oxazol-4-yl)-2-phenylethane-1,1-diyl]bis(phosphonic acid) (7a)

Eluent: petroleum ether-acetone (90/10, v/v). Product 7a was separated as colorless crystals, yield $55 \%$. - M. p. $120-$ $122{ }^{\circ} \mathrm{C}$. - IR (KBr): $v=3320(\mathrm{OH}), 1690(\mathrm{C}=\mathrm{O})$, 
$1640(\mathrm{C}=\mathrm{N}), 1257(\mathrm{P}=\mathrm{O}), 1130(\mathrm{P}-\mathrm{O}) \mathrm{cm}^{-1} .-{ }^{1} \mathrm{H}$ NMR $\left(500.14 \mathrm{MHz}, \mathrm{CDCl}_{3}\right): \delta=1.88\left(1 \mathrm{H}, \mathrm{ddd}, J_{\mathrm{HH}}=7.0 \mathrm{~Hz}\right.$, $\left.{ }^{2} J_{\mathrm{HP}}=30.0 \mathrm{~Hz}, \mathrm{CH}-\mathrm{P}_{2}\right), 3.34,3.36(1 \mathrm{H}, 2 \mathrm{dd}$ each set with $\left.J_{\mathrm{HH}}=7.6 \mathrm{~Hz}, J_{\mathrm{HP}}=11.5 \mathrm{~Hz} C H-\mathrm{CH}-\mathrm{P}_{2}\right), 4.3(1 \mathrm{H}$, $\mathrm{d}, J_{\mathrm{HH}}=7.0,5.0 \mathrm{~Hz}$, cyclic $\left.\mathrm{CH}\right), 6.30(4 \mathrm{H}, \mathrm{s}, 4 \mathrm{OH}$, exchangeable with $\left.\mathrm{D}_{2} \mathrm{O}\right), 7.4-7.8\left(\mathrm{~m}, 10 \mathrm{H}, \mathrm{H}_{\text {arom }}\right) .-{ }^{13} \mathrm{C} \mathrm{NMR}$ $\left(125.76 \mathrm{MHz}, \mathrm{CDCl}_{3}\right): \delta=17.5\left(\mathrm{~d},{ }^{2} J_{\mathrm{CP}}=28.5 \mathrm{~Hz}\right.$, $\left.\mathrm{CH}-\mathrm{CH}-\mathrm{P}_{2}\right), 34.2,34.2\left(\mathrm{dd}, J_{\mathrm{CP}}=130 \mathrm{~Hz}, \mathrm{CH}-\mathrm{P}_{2}\right), 71.9$ (cyclic $\mathrm{CH}), 126.4-148.8$ (aromatic $\mathrm{CH}), 157.8(\mathrm{C}=\mathrm{N})$, 165.6 (C=O). $-{ }^{31} \mathrm{P}$ NMR: $\delta=23.7 .-$ MS (EI, $\left.70 \mathrm{eV}\right)$ : $m / z(\%)=424(50)[\mathrm{M}]^{+} .-\mathrm{C}_{17} \mathrm{H}_{17} \mathrm{NO}_{8} \mathrm{P}_{2}$ (425.04): calcd. C 48.01, H 4.03, N 3.29, P 14.57; found C 48.40, H 4.01, N 3.20, P 13.25.

\section{2-[(4,5-Dihydro-5-oxo-2-phenyloxazol-4-yl)-2-phenyl- vinyl]phosphonic acid $(\mathbf{8 a})$}

Eluent: petroleum ether-acetone $(95 / 5, \mathrm{v} / \mathrm{v})$. Product 8a was separated as yellow crystals, yield $25 \%$. M.p. $120{ }^{\circ} \mathrm{C}$. $-\mathrm{IR}(\mathrm{KBr}): v=3325(\mathrm{OH}), 1690(\mathrm{C}=\mathrm{O})$, $1635(\mathrm{C}=\mathrm{N}), 1610(\mathrm{C}=\mathrm{C}), 1220(\mathrm{P}=\mathrm{O}) \mathrm{cm}^{-1} .-{ }^{1} \mathrm{H}$ NMR (500.76 MHz, [D 6 ]DMSO): $\delta=4.65(1 \mathrm{H}, \mathrm{s}$, cyclic $\mathrm{CH}), 5.1$ $\left(1 \mathrm{H}, \mathrm{d},{ }^{2} J_{\mathrm{HP}}=20.0 \mathrm{~Hz}, \mathrm{CH}-\mathrm{P}\right), 6.1(2 \mathrm{H}, \mathrm{s}, 2 \mathrm{OH}$, exchangeable with $\left.\mathrm{D}_{2} \mathrm{O}\right), 7.2-8.1\left(\mathrm{~m}, 10 \mathrm{H}, \mathrm{H}_{\text {arom }}\right) .-{ }^{13} \mathrm{C} \mathrm{NMR}$ (125.76 MHz, [D 6 ]DMSO): $\delta=75.8$ (cyclic CH), $103.8(\mathrm{~d}$, $J_{\mathrm{CP}}=93.2 \mathrm{~Hz}, \mathrm{C}-\mathrm{P}$ ), $121.0-147.6$ (aromatic C-H), 157.8 $(\mathrm{C}=\mathrm{N}), 166.0(\mathrm{C}=\mathrm{O}) .-{ }^{31} \mathrm{P} \mathrm{NMR}: \delta=20.5$. $-\mathrm{MS}(\mathrm{EI}$, $70 \mathrm{eV}): m / z(\%)=343(50)[\mathrm{M}]^{+} .-\mathrm{C}_{17} \mathrm{H}_{14} \mathrm{NO}_{5} \mathrm{P}$ (343.27): calcd. C 59.48, H 4.11, N 4.08, P 9.02; found C 59.40, H 4.10, N 4.10, P 9.04.

\section{[2-(4-Nitrophenyl)-2-(5-oxo-2-phenyl-4,5-dihydro-1,3-} oxazol-4-yl)ethane-1,1-diyl]bis(phosphonic acid) (7b)

Eluent: petroleum ether-acetone (70/30, v/v). Product $7 \mathbf{b}$ was separated as yellow crystals, yield 50\%. - M.p. 159 $160{ }^{\circ} \mathrm{C}$. - IR (KBr): $v=3320(\mathrm{OH}), 1690(\mathrm{C}=\mathrm{O}), 1640$ $(\mathrm{C}=\mathrm{N}), 1344\left(\mathrm{NO}_{2}\right), 1249(\mathrm{P}=\mathrm{O}), 1130(\mathrm{P}-\mathrm{O}) \mathrm{cm}^{-1}$. ${ }^{1} \mathrm{H}$ NMR (500.76 MHz, [D 6 ]DMSO): $\delta=1.85,1.89(1 \mathrm{H}$, $\left.\mathrm{ddd}, J_{\mathrm{HH}}=7 \mathrm{~Hz},{ }^{2} J_{\mathrm{HP}}=30 \mathrm{~Hz} \mathrm{CH}-\mathrm{P}_{2}\right), 3.43,3.45(1 \mathrm{H}$, $2 \mathrm{dd}$ each set with $J_{\mathrm{HH}}=7.6 \mathrm{~Hz}, J_{\mathrm{HP}}=21.5 \mathrm{~Hz}, \mathrm{CH}$ $\mathrm{CH}-\mathrm{P}), 4.3\left(1 \mathrm{H}, \mathrm{dd}, \mathrm{J}_{\mathrm{HH}}=7,5 \mathrm{~Hz}\right.$, cyclic $\left.\mathrm{CH}\right), 7.4-8.2$ $\left(9 \mathrm{H}_{\text {arom }}, \mathrm{m}, 9 \mathrm{CH}\right), 10.1(4 \mathrm{H}, \mathrm{s}, 4-\mathrm{OH}$, exchangeable with $\left.\mathrm{D}_{2} \mathrm{O}\right) .-{ }^{13} \mathrm{C}$ NMR $\left(125.76 \mathrm{MHz},\left[\mathrm{D}_{6}\right] \mathrm{DMSO}\right): \delta=17.50$, $17.53\left(\mathrm{~d},{ }^{2} J_{\mathrm{CP}}=30 \mathrm{~Hz}, \mathrm{CH}-\mathrm{CH}-\mathrm{P}_{2}\right), 34.2,34.3\left(\mathrm{dd}, J_{\mathrm{CP}}=\right.$ $130 \mathrm{~Hz}, \mathrm{CH}-\mathrm{P}_{2}$ ), 71.9 (cyclic $\mathrm{CH}$ ), 120.8-154.1 (aromatic $\mathrm{CH}), 157.8(\mathrm{C}=\mathrm{N}), 165.6(\mathrm{C}=\mathrm{O}) .-{ }^{31} \mathrm{P}$ NMR: $\delta=23.8$. $-\mathrm{MS}$ (EI, $70 \mathrm{eV}): m / z(\%)=470(55)[\mathrm{M}]^{+} .-\mathrm{C}_{17} \mathrm{H}_{16} \mathrm{~N}_{2} \mathrm{O}_{10} \mathrm{P}_{2}$ (470.17): calcd. C 43.42, H 3.43, N 5.96, P 13.17; found C 43.80, H 3.42, N 5.90, P 13.50 .

[2-(4-Nitrophenyl)-2-(5-oxo-2-phenyl-4,5-dihydro-1,3-oxazol-4-yl)ethenyl]phosphonic acid $(\mathbf{8 b})$

Eluent: petroleum ether-acetone (95/5, v/v). Product $\mathbf{8 b}$ was separated as yellow crystals, yield $20 \%$. -
M. p. $130{ }^{\circ} \mathrm{C} .-\mathrm{IR}(\mathrm{KBr}): v=3320(\mathrm{OH}), 1690(\mathrm{C}=\mathrm{O})$, $1640(\mathrm{C}=\mathrm{N}), 1610(\mathrm{C}=\mathrm{C}), 1344\left(\mathrm{NO}_{2}\right), 1225(\mathrm{P}=\mathrm{O}) \mathrm{cm}^{-1}$. ${ }^{1} \mathrm{H}$ NMR $\left(500.14 \mathrm{MHz}, \mathrm{CDCl}_{3}\right): \delta=4.65(1 \mathrm{H}, \mathrm{s}$, cyclic $\mathrm{CH}), 5.4\left(1 \mathrm{H}, \mathrm{d},{ }^{2} J_{\mathrm{HP}}=20 \mathrm{~Hz}, \mathrm{CH}-\mathrm{P}\right), 6.2(2 \mathrm{H}, \mathrm{s}, 2 \mathrm{OH}$, exchangeable with $\left.\mathrm{D}_{2} \mathrm{O}\right), 7.2-8.1\left(\mathrm{~m}, 9 \mathrm{H}, \mathrm{H}_{\text {arom }}\right) .-{ }^{13} \mathrm{C}$ NMR (125.76 MHz, [D $\mathrm{D}_{6}$ ]DMSO): $\delta=75.8$ (cyclic $\left.\mathrm{CH}\right), 109.8(\mathrm{~d}$, $J_{\mathrm{CP}}=93.2 \mathrm{~Hz}, \mathrm{C}-\mathrm{P}$ ), $125.0-147.6$ (aromatic C-H), 154.8 $(\mathrm{C}=\mathrm{N}), 165.0(\mathrm{C}=\mathrm{O}) .-{ }^{31} \mathrm{P}$ NMR: $\delta=22.5$. $-\mathrm{MS}(\mathrm{EI}$, $70 \mathrm{eV}): m / z(\%)=388.27(40)[\mathrm{M}]^{+} .-\mathrm{C}_{21} \mathrm{H}_{21} \mathrm{~N}_{2} \mathrm{O}_{7} \mathrm{P}$ (388.27): calcd. C 52.59, H 3.37, N 7.21, P 7.98; found C 52.60, H 3.21, N 7.20, P 7.93.

General procedure for reactions of 4-arylidene-2-phenyl$5(4 H)$-oxazolones $(\mathbf{1 a}, \mathbf{1} \boldsymbol{c})$ with carbalkoxymethylene triphenylphosphoranes $(\mathbf{3 a}, \mathbf{3 b})$

One mmol of $\mathbf{1 a}$ or $\mathbf{1 c}$ was added to $3 \mathrm{mmol}$ of $\mathbf{3 a}$ or $\mathbf{3 b}$, and the mixture was refluxed in $30 \mathrm{~mL}$ of dry toluene for $5-$ $7 \mathrm{~h}$. The volatile materials were evaporated under reduced pressure. The residue was subjected to silica gel column chromatography to give the products $9 \mathbf{a}-\mathbf{c}, 10 \mathbf{a}-\mathbf{c}$ and $11 \mathbf{a}-$ c. Triphenylphosphane was also isolated from the reaction medium and identified (mixed m. p., MS). Products 9a-c were refluxed in dry toluene to give products $\mathbf{1 0 a}-\mathbf{c}$ (cyclic form) in $85 \%$ yield.

Methyl 3-(4,5-dihydro-5-oxo-2-phenyloxazol-4-yl)-3-phenylacrylate $(9 a)$

Eluent: petroleum ether-acetone $(85 / 15$, v/v). Product 9a was separated as colorless crystals, yield $27 \%$. M.p. $90{ }^{\circ} \mathrm{C}$. - IR (KBr): $v=1741$ (ester $\left.\mathrm{C}=\mathrm{O}\right), 1690$ $(\mathrm{O}-\mathrm{C}=\mathrm{O}), 1654(\mathrm{C}=\mathrm{N}) \mathrm{cm}^{-1} .-{ }^{1} \mathrm{H}$ NMR $(500.14 \mathrm{MHz}$, $\left.\mathrm{CDCl}_{3}\right): \delta=3.5\left(3 \mathrm{H}, \mathrm{s}, \mathrm{CH}_{3}\right), 4.65(1 \mathrm{H}, \mathrm{s}$, cyclic $\mathrm{CH})$, $5.88(1 \mathrm{H}, \mathrm{s}, \mathrm{CHCOOCH}), 7.0-8.0\left(\mathrm{~m}, 10 \mathrm{H}, \mathrm{H}_{\text {arom }}\right)$. ${ }^{13} \mathrm{C}$ NMR $\left(125.76 \mathrm{MHz}, \mathrm{CDCl}_{3}\right): \delta=52.7\left(\mathrm{CH}_{3}\right), 73.9$ (cyclic $\mathrm{CH}), 143.2,119.5(\mathrm{C}=\mathrm{CH}), 126.5-135.9$ (aromatic $\mathrm{CH}), 153.9(\mathrm{C}=\mathrm{N}), 166.0($ ester $\mathrm{C}=\mathrm{O}), 176.1(\mathrm{O}-\mathrm{C}=\mathrm{O}) .-\mathrm{MS}$ $(\mathrm{EI}, 70 \mathrm{eV}): m / z(\%)=321(5)[\mathrm{M}]^{+}, 306(100)[\mathrm{M}-15]^{+}$. $\mathrm{C}_{19} \mathrm{H}_{15} \mathrm{NO}_{4}$ (321.10): calcd. C 71.02, $\mathrm{H} 4.71, \mathrm{~N} 4.36$; found C 70.80, H 4.81, N 4.30.

Methyl 2,6-diphenyl-5,6-dihydrofuro[3,2-d][1,3]oxazole-5carboxylate (10a)

Eluent: petroleum ether-acetone (95/5, v/v). Product 10a was separated as colorless crystals, yield $35 \%$. - M. p. $198-$ $200{ }^{\circ} \mathrm{C}$. - IR $(\mathrm{KBr}): v=1741($ ester $\mathrm{C}=\mathrm{O}), 1654(\mathrm{C}=\mathrm{N})$, $1610(\mathrm{C}=\mathrm{C}-\mathrm{O}) \mathrm{cm}^{-1} .-{ }^{1} \mathrm{H}$ NMR $\left(500.14 \mathrm{MHz}, \mathrm{CDCl}_{3}\right): \delta=$ $3.5\left(3 \mathrm{H}, \mathrm{s}, \mathrm{CH}_{3}\right), 5.1(1 \mathrm{H}, \mathrm{d}, \mathrm{CH}-\mathrm{Ar}), 5.29(1 \mathrm{H}, \mathrm{d}$, cyclic $\mathrm{CH}), 7.1-7.9\left(\mathrm{~m}, 10 \mathrm{H}, \mathrm{H}_{\text {arom }}\right) .-{ }^{13} \mathrm{C} \mathrm{NMR}(125.76 \mathrm{MHz}$, $\left.\mathrm{CDCl}_{3}\right): \delta=45.5(\mathrm{CH}-\mathrm{Ar}), 54.0\left(\mathrm{CH}_{3}\right), 84.4$ (cyclic $\left.\mathrm{CH}\right)$, 125.4, 138.1 $(\mathrm{C}=\mathrm{C}), 126.5-144.2$ (aromatic $\mathrm{CH}), 153.6$ $(\mathrm{C}=\mathrm{N}), 167.05($ ester $\mathrm{C}=\mathrm{O})$. $-\mathrm{MS}(\mathrm{EI}, 70 \mathrm{eV}): \mathrm{m} / \mathrm{z}(\%)=$ $321(25)[\mathrm{M}]^{+}, 306(100)[\mathrm{M}-15]^{+} .-\mathrm{C}_{19} \mathrm{H}_{15} \mathrm{NO}_{4}$ (321.10): 
calcd. C 71.02, H 4.71, N 4.36; found C 70.80, H 4.81, N 4.20.

Methyl (5-oxo-2,7-diphenyl-5H-pyrano[3,2-d][1,3]oxazol$6(7 H)$-ylidene) ethanoate (11a)

Eluent: petroleum ether-acetone (70/30, v/v). Product 11a was separated as pale-yellow crystals, yield $22 \%$. M. p. $268-270^{\circ} \mathrm{C}$. $-\mathrm{IR}(\mathrm{KBr}): v=1742($ ester $\mathrm{C}=\mathrm{O}), 1690$ $(\mathrm{O}-\mathrm{C}=\mathrm{O}), 1653(\mathrm{C}=\mathrm{N}) \mathrm{cm}^{-1} .-{ }^{1} \mathrm{H}$ NMR $(500.14 \mathrm{MHz}$, $\left.\mathrm{CDCl}_{3}\right): \delta=3.7\left(3 \mathrm{H}, \mathrm{s}, \mathrm{CH}_{3}\right), 4.7(1 \mathrm{H}, \mathrm{s}$, cyclic $\mathrm{CH})$, $6.2(1 \mathrm{H}, \mathrm{s}, \mathrm{CH}), 7.0-7.9\left(\mathrm{~m}, 10 \mathrm{H}, \mathrm{H}_{\mathrm{arom}}\right) .-{ }^{13} \mathrm{C} \mathrm{NMR}$ $\left(125.76 \mathrm{MHz}, \mathrm{CDCl}_{3}\right): \delta=38.7$ (cyclic $\left.\mathrm{CH}\right), 52.2\left(\mathrm{CH}_{3}\right)$, 125.4, 138.1 (C=C), 126.4-135.5 (aromatic $\mathrm{CH}$ ), 153.2 $(\mathrm{C}=\mathrm{N}), 166.5$ (ester $\mathrm{C}=\mathrm{O}), 176.0(\mathrm{O}-\mathrm{C}=\mathrm{O})$. - MS (EI, $70 \mathrm{eV}): m / z(\%)=361(55)[\mathrm{M}]^{+} .-\mathrm{C}_{21} \mathrm{H}_{15} \mathrm{NO}_{5}$ (361.10): calcd. C 69.80, H 4.18, N 3.88; found C 68.99, H 4.60, N 4.12 .

Ethyl 3-(5-oxo-2-phenyl-4,5-dihydro-1,3-oxazol-4-yl)3-phenylprop-2-enoate (9b)

Eluent: petroleum ether-ethyl acetate $(90 / 10, v / v)$. Product 9a was separated as colorless crystals, yield $30 \%$. M.p. $99{ }^{\circ} \mathrm{C}$. - IR (KBr): $v=1742$ (ester $\left.\mathrm{C}=\mathrm{O}\right), 1690$ $(\mathrm{O}-\mathrm{C}=\mathrm{O}), 1653(\mathrm{C}=\mathrm{N}) \mathrm{cm}^{-1}$. $-{ }^{1} \mathrm{H}$ NMR $(500.14 \mathrm{MHz}$, $\left.\mathrm{CDCl}_{3}\right): \delta=1.1\left(3 \mathrm{H}, \mathrm{t}, \mathrm{CH}_{3}\right), 4.1\left(2 \mathrm{H}, \mathrm{q}, \mathrm{CH}_{2}\right), 4.7$ $(1 \mathrm{H}, \mathrm{s}$, cyclic $\mathrm{CH}), 5.8(1 \mathrm{H}, \mathrm{s}, \mathrm{CH}), 7.1-8.0(\mathrm{~m}, 10 \mathrm{H}$, $\left.\mathrm{H}_{\text {arom }}\right) .-{ }^{13} \mathrm{C} \mathrm{NMR}\left(125.76 \mathrm{MHz}, \mathrm{CDCl}_{3}\right): \delta=14.1\left(\mathrm{CH}_{3}\right)$, $61.4\left(\mathrm{CH}_{2}\right), 73.7$ (cyclic $\left.\mathrm{CH}\right), 126.6-136.4$ (aromatic $\left.\mathrm{CH}\right)$, 152.2, $119.2(\mathrm{C}=\mathrm{CH}), 154.9(\mathrm{C}=\mathrm{N}), 166.2($ ester $\mathrm{C}=\mathrm{O}), 176.1$ $(\mathrm{O}-\mathrm{C}=\mathrm{O}) .-\mathrm{MS}(\mathrm{EI}, 70 \mathrm{eV}): \mathrm{m} / z(\%)=335(10)[\mathrm{M}]^{+}$, 318 (75) $[\mathrm{M}-15]^{+} .-\mathrm{C}_{20} \mathrm{H}_{17} \mathrm{NO}_{4}$ (335.12): calcd. C 71.63, H 5.11, N 4.18; found C 71.89, H 5.67, N 4.02.

Ethyl 2,6-diphenyl-5,6-dihydrofuro[3,2-d][1,3]oxazole-5carboxylate $(\mathbf{1 0 b})$

Eluent: petroleum ether-ethyl acetate $(95 / 5, \mathrm{v} / \mathrm{v})$. Product 10a was separated as colorless crystals, yield $37 \%$. M. p. $210-212^{\circ} \mathrm{C}$. $-\mathrm{IR}(\mathrm{KBr}): v=1740$ (ester $\left.\mathrm{C}=\mathrm{O}\right), 1690$ $(\mathrm{C}=\mathrm{C}-\mathrm{O}), 1654(\mathrm{C}=\mathrm{N}) \mathrm{cm}^{-1}$. $-{ }^{1} \mathrm{H}$ NMR $(500.14 \mathrm{MHz}$, $\left.\mathrm{CDCl}_{3}\right): \delta=1.1\left(3 \mathrm{H}, \mathrm{t}, \mathrm{CH}_{3}\right), 4.1\left(2 \mathrm{H}, \mathrm{q}, \mathrm{CH}_{2}\right), 5.1(1 \mathrm{H}, \mathrm{d}$, $\mathrm{CH}-\mathrm{Ar}), 5.3(1 \mathrm{H}, \mathrm{d}$, cyclic $\mathrm{CH}), 7.1-8.0\left(\mathrm{~m}, 10 \mathrm{H}, \mathrm{H}_{\text {arom }}\right)$. ${ }^{13} \mathrm{C}$ NMR $\left(125.76 \mathrm{MHz}, \mathrm{CDCl}_{3}\right): \delta=14.0\left(\mathrm{CH}_{3}\right), 44.7$ (CH-Ar), $61.6\left(\mathrm{CH}_{2}\right), 84.1$ (cyclic $\left.\mathrm{CH}\right), 125.4(\mathrm{C}=\mathrm{C}), 126.6-$ $140.3(\operatorname{aromatic} \mathrm{CH}), 154.5(\mathrm{C}=\mathrm{N}), 169.5($ ester $\mathrm{C}=\mathrm{O}) .-\mathrm{MS}$ $(\mathrm{EI}, 70 \mathrm{eV}): m / z(\%)=335(10)[\mathrm{M}]^{+}, 319(100)[\mathrm{M}-15]^{+} .-$ $\mathrm{C}_{20} \mathrm{H}_{17} \mathrm{NO}_{4}$ (335.12): calcd. C 71.63, H 5.11, N 4.18; found C 70.96, H 5.60, N 4.08.

Ethyl (5-oxo-2,7-diphenyl-5H-pyrano[3,2-d][1,3]oxazol$6(7 H)$-ylidene)ethanoate (11b)

Eluent: petroleum ether-ethyl acetate $(70 / 30, v / v)$. Product 11b was separated as yellow crystals, yield $20 \%$. M. p. $240-242^{\circ} \mathrm{C}$. - IR (KBr): $v=1742$ (ester C=O), 1690
$(\mathrm{O}-\mathrm{C}=\mathrm{O}), 1652(\mathrm{C}=\mathrm{N}) \mathrm{cm}^{-1} .-{ }^{1} \mathrm{H}$ NMR $(500.14 \mathrm{MHz}$, $\left.\mathrm{CDCl}_{3}\right): \delta=1.2\left(3 \mathrm{H}, \mathrm{t}, \mathrm{CH}_{3}\right), 4.1\left(2 \mathrm{H}, \mathrm{q}, \mathrm{CH}_{2}\right), 4.7(1 \mathrm{H}$, s, cyclic $\mathrm{CH}), 6.2(1 \mathrm{H}, \mathrm{s}, \mathrm{CH}), 7.0-8.0\left(\mathrm{~m}, 10 \mathrm{H}, \mathrm{H}_{\text {arom }}\right)$. ${ }^{13} \mathrm{C}$ NMR $\left(125.76 \mathrm{MHz}, \mathrm{CDCl}_{3}\right): \delta=14.3\left(\mathrm{CH}_{3}\right), 38.8$ (cyclic $\mathrm{CH}), 61.5\left(\mathrm{CH}_{2}\right), 145.4,119.1(\mathrm{C}=\mathrm{CH}), 126.5-$ 138.5 (aromatic $\mathrm{CH}), 153.9(\mathrm{C}=\mathrm{N}), 166.4($ ester $\mathrm{C}=\mathrm{O}), 176.4$ $(\mathrm{O}-\mathrm{C}=\mathrm{O}) .-\mathrm{MS}(\mathrm{EI}): m / z(\%)=375(10)[\mathrm{M}]^{+}, 359(70)$ $[\mathrm{M}-15]^{+} .-\mathrm{C}_{22} \mathrm{H}_{17} \mathrm{NO}_{5}$ (375.11): calcd. C 70.39, H 4.56, N 3.73; found C 70.02, H 4.75, N 3.32 .

Methyl 3-[4-(dimethylamino)phenyl]-3-(5-oxo-2-phenyl4,5-dihydro-1,3-oxazol-4-yl)prop-2-enoate (9c)

Eluent: petroleum ether-acetone $(95 / 5, \mathrm{v} / \mathrm{v})$. Product 9c was separated as colorless crystals, yield $35 \%$. - M. p. $228-$ $230{ }^{\circ} \mathrm{C}$. $-\mathrm{IR}(\mathrm{KBr}): v=1741$ (ester $\left.\mathrm{C}=\mathrm{O}\right), 1690(\mathrm{O}-\mathrm{C}=\mathrm{O})$, $1653(\mathrm{C}=\mathrm{N}) \mathrm{cm}^{-1} .-{ }^{1} \mathrm{H}$ NMR $\left(500.14 \mathrm{MHz}, \mathrm{CDCl}_{3}\right): \delta=$ 2.85, $2.86\left(6 \mathrm{H}, 2 \mathrm{~s}, \mathrm{~N}\left(\mathrm{CH}_{3}\right)_{2}\right), 3.7\left(3 \mathrm{H}, \mathrm{s}, \mathrm{CH}_{3}\right), 4.6(1 \mathrm{H}, \mathrm{s}$, cyclic $\mathrm{CH}), 5.8(1 \mathrm{H}, \mathrm{s}, \mathrm{CHCOO}), 7.0-7.9\left(\mathrm{~m}, 9 \mathrm{H}, \mathrm{H}_{\text {arom }}\right)$. ${ }^{13} \mathrm{C}$ NMR (125.76 MHz, $\left.\mathrm{CDCl}_{3}\right): \delta=40.3\left(\mathrm{~N}\left(\mathrm{CH}_{3}\right)_{2}\right)$, $53.2\left(\mathrm{CH}_{3}\right), 73.3$ (cyclic $\left.\mathrm{CH}\right), 126.9-138.1$ (aromatic $\left.\mathrm{CH}\right)$, 150.7, $120(\mathrm{C}=\mathrm{CH}), 154.0(\mathrm{C}=\mathrm{N}), 166.2($ ester $\mathrm{C}=\mathrm{O}), 176.2$ $(\mathrm{O}-\mathrm{C}=\mathrm{O}) .-\mathrm{MS}(\mathrm{EI}, 70 \mathrm{eV}): \mathrm{m} / z(\%)=364(50)[\mathrm{M}]^{+} .-$ $\mathrm{C}_{21} \mathrm{H}_{20} \mathrm{~N}_{2} \mathrm{O}_{4}$ (364.14): calcd. C 69.22, H 5.53, N 7.69; found C 70.30, H 5.28, N 8.01.

Methyl 6-[4-(dimethylamino)phenyl]-2-phenyl-5,6-dihydrofuro[3,2-d][1,3]oxazole-5-carboxylate (10c)

Eluent: petroleum ether-acetone (95/5, v/v). Product 10c was separated as pale-yellow crystals, yield $30 \%$. M. p. $290-291{ }^{\circ} \mathrm{C}$. - IR $(\mathrm{KBr}): v=1741$ (ester C=O), 1690 $(\mathrm{C}=\mathrm{C}-\mathrm{O}), 1654(\mathrm{C}=\mathrm{N}) \mathrm{cm}^{-1} .-{ }^{1} \mathrm{H}$ NMR $(500.14 \mathrm{MHz}$, $\left.\mathrm{CDCl}_{3}\right): \delta=2.84,2.85\left(6 \mathrm{H}, 2 \mathrm{~s}, \mathrm{~N}\left(\mathrm{CH}_{3}\right)_{2}\right), 3.6(3 \mathrm{H}$, s, $\left.\mathrm{CH}_{3}\right), 5.2(1 \mathrm{H}, \mathrm{d}, \mathrm{CH}-\mathrm{Ar}), 5.3(1 \mathrm{H}, \mathrm{d}, \mathrm{CH}), 7.0-8.0$ $\left(\mathrm{m}, 9 \mathrm{H}, \mathrm{H}_{\text {arom }}\right) \cdot-{ }^{13} \mathrm{C} \mathrm{NMR}\left(125.76 \mathrm{MHz}, \mathrm{CDCl}_{3}\right): \delta=$ $40.3\left(\mathrm{~N}\left(\mathrm{CH}_{3}\right)_{2}\right), 45.0(\mathrm{CH}-\mathrm{Ar}), 53.6\left(\mathrm{CH}_{3}\right), 91.9$ (cyclic $\mathrm{CH}), 125.4(\mathrm{C}=\mathrm{C}), 126.6-138.9$ (aromatic $\mathrm{CH}), 153.2$ $(\mathrm{C}=\mathrm{N}), 166.9($ ester $\mathrm{C}=\mathrm{O})$. $-\mathrm{MS}(\mathrm{EI}, 70 \mathrm{eV}): \mathrm{m} / z(\%)=364$ (15) $[\mathrm{M}]^{+}, 348(100)[\mathrm{M}-15]^{+} .-\mathrm{C}_{21} \mathrm{H}_{20} \mathrm{~N}_{2} \mathrm{O}_{4}$ (364.14): calcd. C 69.22, H 5.53, N 7.69; found C 69.30, H 5.28, N 8.01.

Methyl \{7-[4-(dimethylamino)phenyl]-5-oxo-2-phenyl-5Hpyrano[3,2-d][1,3]oxazol-6(7H)-ylidene\}ethanoate (11c)

Eluent: petroleum ether-acetone (65/35, v/v). Product 11c was separated as pale yellow crystals, yield $30 \%$. M. p. $250-253{ }^{\circ} \mathrm{C}$. $-\mathrm{IR}(\mathrm{KBr}): v=1740$ (ester $\left.\mathrm{C}=\mathrm{O}\right), 1690$ $(\mathrm{O}-\mathrm{C}=\mathrm{O}), 1652(\mathrm{C}=\mathrm{N}) \mathrm{cm}^{-1}$. - ${ }^{1} \mathrm{H}$ NMR $(500.14 \mathrm{MHz}$, $\left.\mathrm{CDCl}_{3}\right): \delta=2.84,2.85\left(6 \mathrm{H}, 2 \mathrm{~s}, \mathrm{~N}\left(\mathrm{CH}_{3}\right)_{2}\right), 3.6(3 \mathrm{H}, \mathrm{s}$, $\left.\mathrm{CH}_{3}\right), 4.7(1 \mathrm{H}, \mathrm{s}$, cyclic $\mathrm{CH}), 6.4(1 \mathrm{H}, \mathrm{s}, \mathrm{CH}), 7.0-8.0(\mathrm{~m}$, $\left.9 \mathrm{H}, \mathrm{H}_{\text {arom }}\right) .-{ }^{13} \mathrm{C}$ NMR $\left(125.76 \mathrm{MHz}, \mathrm{CDCl}_{3}\right): \delta=38.1$ (cyclic $\mathrm{CH}), 40.6\left(\mathrm{~N}\left(\mathrm{CH}_{3}\right)_{2}\right), 52.6\left(\mathrm{CH}_{3}\right), 126.6-138.3$ (aro- 
matic $\mathrm{CH}), 143.2,119.1(\mathrm{C}=\mathrm{CH}), 153.3(\mathrm{C}=\mathrm{N}), 166.4$ (ester $\mathrm{C}=\mathrm{O}), 170.4(\mathrm{O}-\mathrm{C}=\mathrm{O}) .-\mathrm{MS}(\mathrm{EI}, 70 \mathrm{eV}): \mathrm{m} / z(\%)=404$ (25) $[\mathrm{M}]^{+} .-\mathrm{C}_{23} \mathrm{H}_{20} \mathrm{~N}_{2} \mathrm{O}_{5}$ (404.14): calcd. C 68.31, H 4.98, N 6.93; found C 69.02, H 4.39, N 6.90.

Reaction of 4-(4-nitrobenzylidene)-2-phenyl-1,3-oxazol$5(4 H)$-one $(\mathbf{1 b})$ with ethyl (triphenyl- $\lambda^{5}$-phosphanylidene)acetate $(3 \boldsymbol{b})$

$0.29 \mathrm{~g}(1 \mathrm{mmol})$ of $\mathbf{1 b}$ was added to $0.7 \mathrm{~g}(2 \mathrm{mmol})$ of $\mathbf{3 b}$, and the mixture was allowed to reflux in $30 \mathrm{~mL}$ dry toluene for $10 \mathrm{~h}$ (TLC). The volatile materials were evaporated under reduced pressure. The residue was chromatographed to give the products 9d and 10d. Triphenylphosphane was also isolated from the reaction medium and identified (mixed m.p., MS).

Ethyl 3-[3-(4-nitrophenyl)-3-(4,5-dihydro-5-oxo)-2-phenyloxazol-4-yl]acrylate $(\mathbf{9 d})$

Eluent: petroleum ether-acetone (90/10, v/v). Product 9d was separated as yellow crystals, yield $25 \%$. - M. p. 195$196{ }^{\circ} \mathrm{C}$. - IR $(\mathrm{KBr}): v=1740($ ester $\mathrm{C}=\mathrm{O}), 1690(\mathrm{O}-\mathrm{C}=\mathrm{O})$, $1654(\mathrm{C}=\mathrm{N}), 1344\left(\mathrm{NO}_{2}\right) \mathrm{cm}^{-1} .-{ }^{1} \mathrm{H}$ NMR $(500.14 \mathrm{MHz}$, $\left.\mathrm{CDCl}_{3}\right): \delta=1.02\left(3 \mathrm{H}, \mathrm{t}, \mathrm{CH}_{3}\right), 4.1\left(2 \mathrm{H}, \mathrm{q}, \mathrm{CH}_{2}\right), 4.7$ $(1 \mathrm{H}, \mathrm{s}$, cyclic $\mathrm{CH}), 5.8(1 \mathrm{H}, \mathrm{s}, \mathrm{CHCOO}), 7.4-8.2(\mathrm{~m}, 9 \mathrm{H}$, $\left.\mathrm{H}_{\text {arom }}\right) .-{ }^{13} \mathrm{C} \mathrm{NMR}\left(125.76 \mathrm{MHz}, \mathrm{CDCl}_{3}\right): \delta=14.3\left(\mathrm{CH}_{3}\right)$, $61.3\left(\mathrm{CH}_{2}\right), 74.2($ cyclic $\mathrm{CH}), 149.9,119.2(\mathrm{C}=\mathrm{CH}), 121.2$ 147.6 (aromatic $\mathrm{CH}), 154.2(\mathrm{C}=\mathrm{N}), 166.0($ ester, $\mathrm{C}=\mathrm{O}), 176.9$ $(\mathrm{O}-\mathrm{C}=\mathrm{O}) .-\mathrm{MS}(\mathrm{EI}, 70 \mathrm{eV}): m / z(\%)=380(35)[\mathrm{M}]^{+} .-$ $\mathrm{C}_{20} \mathrm{H}_{16} \mathrm{~N}_{2} \mathrm{O}_{6}$ (380.17): calcd. C 63.16, H 4.24, N 7.37; found C 63.00, H 4.63, N 6.89.

Ethyl 6-(4-nitrophenyl)-2-phenyl-5,6-dihydrofuro[3,2-d][1,3]oxazole-5-carboxylate (10d)

Eluent: petroleum ether-acetone $(95 / 5, \mathrm{v} / \mathrm{v})$. Product 10d was separated as yellow crystals, yield $40 \%$. - M.p. $183-$ $185^{\circ} \mathrm{C}$. - IR (KBr): $v=1740$ (ester $\left.\mathrm{C}=\mathrm{O}\right), 1654(\mathrm{C}=\mathrm{N})$, $1620(\mathrm{C}=\mathrm{C}-\mathrm{O}), 1344\left(\mathrm{NO}_{2}\right) \mathrm{cm}^{-1} .-{ }^{1} \mathrm{H}$ NMR $(500.14 \mathrm{MHz}$, $\left.\mathrm{CDCl}_{3}\right): \delta=1.2\left(3 \mathrm{H}, \mathrm{t}, \mathrm{CH}_{3}\right), 5.2(1 \mathrm{H}, \mathrm{d}, \mathrm{CH}-\mathrm{Ar}), 4.18(2 \mathrm{H}$, q, $\left.\mathrm{CH}_{2}\right), 5.3(1 \mathrm{H}, \mathrm{d}$, cyclic $\mathrm{CH}), 7.4-8.3\left(\mathrm{~m}, 9 \mathrm{H}, \mathrm{H}_{\text {arom }}\right)$. ${ }^{13} \mathrm{C}$ NMR $\left(125.76 \mathrm{MHz}, \mathrm{CDCl}_{3}\right): \delta=14.3\left(\mathrm{CH}_{3}\right), 45.5$ (CH-Ar), $61.4\left(\mathrm{CH}_{2}\right), 73.9(\mathrm{CHCOO}), 125.2(\mathrm{C}=\mathrm{C}), 128.9$ 147.6 (aromatic $\mathrm{CH}), 154.8(\mathrm{C}=\mathrm{N}), 166.0($ ester $\mathrm{C}=\mathrm{O})$. MS (EI, $70 \mathrm{eV}): m / z(\%)=380(40)[\mathrm{M}]^{+} .-\mathrm{C}_{20} \mathrm{H}_{16} \mathrm{~N}_{2} \mathrm{O}_{6}$ (380.17): calcd. C 63.16, H 4.24, N 7.37; found C 63.00, H 4.63, N 6.89 .

General procedure for reactions of 4-arylidene-2-phenyl1,3-oxazol-5(4H)-ones $(\mathbf{1 a}, \boldsymbol{d})$ with (triphenyl- $\lambda^{5}$-phosphanylidene)acetonitrile $(\mathbf{3 c})$

A mixture of 1a, d (1 mmol) and 3c $(0.60 \mathrm{~g}, 2 \mathrm{mmol})$ in $30 \mathrm{~mL}$ of dry toluene was refluxed for $7-10 \mathrm{~h}$ (TLC).
The volatile materials were evaporated under reduced pressure. The residue was chromatographed to give products $\mathbf{1 2}$ and 13. Triphenylphosphane and triphenylphosphane oxide were also isolated from the reaction mixture and identified (mixed m.p., MS).

\section{2,4-Diphenyl-5,6-dihydro-4H-cyclopenta[d][1,3]oxazole- 5,6-dicarbonitrile (12)}

Eluent: petroleum ether-ethyl acetate $(90 / 10, v / v)$. Product 12 was separated as yellow crystals, yield $65 \%$. M. p. $153-155^{\circ} \mathrm{C}$. - IR $(\mathrm{KBr}): v=2210,2215(2 \mathrm{C} \equiv \mathrm{N})$, $1653(\mathrm{C}=\mathrm{N}), 1610(\mathrm{C}=\mathrm{C}) \mathrm{cm}^{-1} .-{ }^{1} \mathrm{H}$ NMR $(500.14 \mathrm{MHz}$, $\left.\mathrm{CDCl}_{3}\right): \delta=4.57(1 \mathrm{H}, \mathrm{dd}, \mathrm{CHCN}), 4.9(1 \mathrm{H}, \mathrm{d}, \mathrm{CHCN})$, $5.5(1 \mathrm{H}, \mathrm{d}, \mathrm{CH}-\mathrm{Ar}), 7.1-7.9\left(\mathrm{~m}, 10 \mathrm{H}, \mathrm{H}_{\text {arom }}\right) .-{ }^{13} \mathrm{C} \mathrm{NMR}$ $\left(125.76 \mathrm{MHz}, \mathrm{CDCl}_{3}\right): \delta=25.6,26.9(2 \mathrm{CHCN}), 37.9$ $(\mathrm{CH}-\mathrm{Ar}), 119.2,120.3(2 \mathrm{C} \equiv \mathrm{N}), 129.3-138.8$ (aromatic $\mathrm{CH}), 153.3(\mathrm{C}=\mathrm{N})$. - MS (EI, $70 \mathrm{eV}): \mathrm{m} / z(\%)=311$ (100) $[\mathrm{M}]^{+} .-\mathrm{C}_{20} \mathrm{H}_{13} \mathrm{~N}_{3} \mathrm{O}$ (311.11): calcd. C 77.16, H 4.21, N 13.50; found C 76.80, H 4.20, N 13.91.

\section{2-[2-Phenyl-4-(3,4,5-trimethoxybenzylidene)-4,5-dihydro- \\ 1,3-oxazol-5-yl]but-2-enedinitrile (13)}

Eluent: petroleum ether-ethyl acetate $(92 / 8, v / v)$. Product 13 was separated as colorless crystals, yield $75 \%$. M. p. $143-145{ }^{\circ} \mathrm{C}$. $-\mathrm{IR}(\mathrm{KBr}): v=2220,2225(2 \mathrm{C} \equiv \mathrm{N})$, $1654(\mathrm{C}=\mathrm{N}), 1610(\mathrm{C}=\mathrm{C}) \mathrm{cm}^{-1} .-{ }^{1} \mathrm{H} \mathrm{NMR}(500.14 \mathrm{MHz}$, [D $\mathrm{D}_{6}$ DMSO): $\delta=3.8\left(9 \mathrm{H}, \mathrm{s}, 3 \mathrm{CH}_{3}\right), 4.5(1 \mathrm{H}, \mathrm{s}$, cyclic $\mathrm{CH})$, $6.1(1 \mathrm{H}, \mathrm{s}, \mathrm{CHCN}), 6.6(1 \mathrm{H}, \mathrm{s}, \mathrm{C}=\mathrm{CH}), 7.2-8.1(\mathrm{~m}, 7 \mathrm{H}$, $\left.7 \mathrm{H}_{\text {arom }}\right) .-{ }^{13} \mathrm{C}$ NMR $\left(125.76 \mathrm{MHz},\left[\mathrm{D}_{6}\right] \mathrm{DMSO}\right): \delta=56.4$ $\left(\mathrm{CH}_{3}\right), 65.0$ (cyclic $\left.\mathrm{CH}\right), 108.6(\mathrm{CHCN}), 119.2,120.0(2$ $\mathrm{C} \equiv \mathrm{N}), 125.6-150.7$ (aromatic $\mathrm{CH}), 154.4(\mathrm{C}=\mathrm{N})$. - MS (EI, $70 \mathrm{eV}): m / z(\%)=401(35)[\mathrm{M}]^{+} .-\mathrm{C}_{23} \mathrm{H}_{19} \mathrm{~N}_{3} \mathrm{O}_{4}(401.41)$ : calcd. C 68.82, H 4.77, N 10.47; found C 69.02, H 4.67, N 11.02.

General procedure for reactions of 4-arylidene-2-phenyl1,3-oxazol-5(4H)-ones $(\mathbf{1 d}, \boldsymbol{e})$ with methyl(triphenyl- $\lambda^{5}$ phosphanylidene)acetate (3a)

A mixture of 1d, e $(0.30 \mathrm{~g}, 1 \mathrm{mmol})$ and $\mathbf{3 a}(0.30 \mathrm{~g}$, $1 \mathrm{mmol})$ was refluxed in dry toluene $(30 \mathrm{~mL})$ for $7 \mathrm{~h}$; the volatile materials were evaporated under reduced pressure. The residue was chromatographed to give product $\mathbf{1 4}$ or $\mathbf{1 5}$. Triphenylphosphane oxide was also isolated from the reaction mixture and identified (mixed m. p. MS).

Methyl [2-phenyl-4-(3,4,5-trimethoxybenzylidene)-1,3-oxazol-5(4H)-ylidene Jethanoate (14)

Eluent: petroleum ether-acetone (90/10, v/v). Product $\mathbf{1 4}$ was separated as colorless crystals, yield $85 \%$. - M. p. $210-$ $212{ }^{\circ} \mathrm{C}$. - IR (KBr): $v=1742($ ester $\mathrm{C}=\mathrm{O}), 1653(\mathrm{C}=\mathrm{N})$, $1610(\mathrm{C}=\mathrm{CH}) \mathrm{cm}^{-1} .-{ }^{1} \mathrm{H}$ NMR $\left(500.14 \mathrm{MHz}, \mathrm{CDCl}_{3}\right): \delta=$ 
$3.6\left(3 \mathrm{H}, \mathrm{s}, \mathrm{CH}_{3}\right), 3.9\left(9 \mathrm{H}, \mathrm{s}, 3 \mathrm{OCH}_{3}\right), 6.2(1 \mathrm{H}, \mathrm{s}, \mathrm{C}=\mathrm{CH})$, $6.6(1 \mathrm{H}, \mathrm{s}, \mathrm{CH}-\mathrm{Ar}), 7.3-8.0\left(\mathrm{~m}, 7 \mathrm{H}, \mathrm{H}_{\mathrm{arom}}\right) .-{ }^{13} \mathrm{C} \mathrm{NMR}$ $\left(125.76 \mathrm{MHz}, \mathrm{CDCl}_{3}\right): \delta=52.9\left(\mathrm{COOCH}_{3}\right), 56.3\left(\mathrm{OCH}_{3}\right)$, 95.7 (CH-Ar), 98.6 (CHCOO), $120.9-150.7$ (aromatic $\mathrm{CH}$ ), $153.6(\mathrm{C}=\mathrm{N}), 195.1,103.1(\mathrm{C}=\mathrm{CH}), 166.2($ ester $\mathrm{C}=\mathrm{O})$. MS (EI, $70 \mathrm{eV}): m / z(\%)=395(30)[\mathrm{M}]^{+} .-\mathrm{C}_{22} \mathrm{H}_{21} \mathrm{NO}_{6}$ (395.14): calcd. C 66.83, H 5.35, N 3.54; found C 67.02, H 5.20, N 4.01.

Methyl 2-(4-(4-methoxybenzylidene)-2-phenyloxazol-5(4H)ylidene) acetate (15)

Eluent: petroleum ether-ethyl acetate (93/7, v/v). Product 15 was separated as colorless crystals, yield $80 \%$. M.p. $245-248{ }^{\circ} \mathrm{C}$. $-\mathrm{IR}(\mathrm{KBr}): v=1742($ ester $\mathrm{C}=\mathrm{O})$, $1653(\mathrm{C}=\mathrm{N}), 1615(\mathrm{C}=\mathrm{CH}) \mathrm{cm}^{-1} .-{ }^{1} \mathrm{H}$ NMR $(500.14 \mathrm{MHz}$, $\left.\mathrm{CDCl}_{3}\right): \delta=3.6\left(3 \mathrm{H}, \mathrm{s}, \mathrm{CH}_{3}\right), 3.7\left(3 \mathrm{H}, \mathrm{s}, \mathrm{OCH}_{3}\right), 6.5$ $(1 \mathrm{H}, \mathrm{s}, \mathrm{C}=\mathrm{CH}), 6.6(1 \mathrm{H}, \mathrm{s}, \mathrm{CH}-\mathrm{Ar}), 7.1-8.0(\mathrm{~m}, 9 \mathrm{H}$, $\left.\mathrm{H}_{\text {arom }}\right) .-{ }^{13} \mathrm{C} \mathrm{NMR}\left(125.76 \mathrm{MHz}, \mathrm{CDCl}_{3}\right): \delta=52.7,55.1(2$ $\left.\mathrm{OCH}_{3}\right), 95.2(\mathrm{CH}-\mathrm{Ar}), 98.6(\mathrm{CHCOO}), 113.4-159.6$ (aromatic $\mathrm{CH}), 153.5(\mathrm{C}=\mathrm{N}), 169.9($ ester $\mathrm{C}=\mathrm{O})$. - MS (EI, $70 \mathrm{eV}): m / z(\%)=335(20)[\mathrm{M}]^{+} .-\mathrm{C}_{20} \mathrm{H}_{17} \mathrm{NO}_{4}$ (335.12): calcd. C 71.63, H 5.11, N 4.18; found C 70.22, H 5.63, $\mathrm{N} 4.52$.

General procedure for reactions of 4-arylidene-2-phenyl1,3-oxazol-5(4H)-ones (1a, $\boldsymbol{c}, \boldsymbol{d})$ with tris(dialkylamino)phosphanes $(\mathbf{4 a}, \boldsymbol{b})$

A mixture of 1a, c, d (1 mmol) and tris(dialkylamino)phosphanes $4 \mathbf{a}, \mathbf{b}(1 \mathrm{mmol})$ in dry dichloromethane $(30 \mathrm{~mL})$ was stirred at r.t. for 5-10 h (TLC). The volatile materials were evaporated under reduced pressure. The residue was washed with boiled cyclohexane to give the products $16 \mathbf{a}-\mathbf{f}$ in pure form.

General procedure for reactions of 4-arylidene-2-phenyl1,3-oxazol-5(4H)-ones $(\mathbf{1} \boldsymbol{a}, \boldsymbol{c}, \boldsymbol{d})$ with secondary amines

4-arylidene-2-phenyl-1,3-oxazol-5(4H)-ones 1a, c, d $(1 \mathrm{mmol})$ and diethylamine or dimethylamine $(1 \mathrm{mmol})$ were warmed for few seconds until complete fusion. The reaction mixture was washed with boiled cyclohexane to give the products 16a-f in good yields (m. p., mixed m. p. and comparative IR).

\section{$N$-[(1-dimethylcarbamoyl)-2-phenylvinyl]benzamide (16a)}

Product 16a was separated as colorless needles, yield $85 \%$. - M. p. $127-128{ }^{\circ} \mathrm{C}$ (ethyl acetate). - IR (KBr): $v=3367(\mathrm{NH}), 1660,1650(2 \mathrm{C}=\mathrm{O}) \mathrm{cm}^{-1} \cdot-{ }^{1} \mathrm{H} \mathrm{NMR}$ (500.14 MHz, $\left.\mathrm{CDCl}_{3}\right): \delta=3.1,3.2\left(6 \mathrm{H}, 2 \mathrm{~s}, \mathrm{~N}\left(\mathrm{CH}_{3}\right)_{2}\right), 6.1$ $(1 \mathrm{H}, \mathrm{s}, \mathrm{CH}), 7.3-7.8\left(\mathrm{~m}, 10 \mathrm{H}, \mathrm{H}_{\text {arom }}\right), 8.5(1 \mathrm{H}, \mathrm{s}, \mathrm{NH}$ exchangeable with $\left.\mathrm{D}_{2} \mathrm{O}\right) .-{ }^{13} \mathrm{C} \mathrm{NMR}\left(125.76 \mathrm{MHz}, \mathrm{CDCl}_{3}\right)$ : $\delta=37.1,37.2\left(2 \mathrm{~s}, \mathrm{~N}\left(\mathrm{CH}_{3}\right)_{2}\right), 115.7,127.8(\mathrm{CH}=\mathrm{C})$,
127.9-131.8 (aromatic CH), 165.7, $168.2(2 \mathrm{C}=\mathrm{O}) .-\mathrm{MS}$ $(\mathrm{EI}, 70 \mathrm{eV}): m / z(\%)=294(50)[\mathrm{M}]^{+} .-\mathrm{C}_{18} \mathrm{H}_{18} \mathrm{~N}_{2} \mathrm{O}_{2}$ (294.14): calcd. C 73.45, H 6.16, N 9.52; found C 72.98, H 6.70, N 9.20.

\section{N-[(1-Diethylcarbamoyl)-2-phenylvinyl]benzamide (16b)}

Product 16b was separated as colorless needles, yield $90 \%$. - M. p. $130-133{ }^{\circ} \mathrm{C}$ (ethyl acetate). - IR (KBr): $v=3368(\mathrm{NH}), 1660,1650(2 \mathrm{C}=\mathrm{O}) \mathrm{cm}^{-1} \cdot-{ }^{1} \mathrm{H}$ NMR $\left(500.14 \mathrm{MHz}, \mathrm{CDCl}_{3}\right): \delta=1.2\left(6 \mathrm{H}, 2 \mathrm{t}, 2 \mathrm{CH}_{3}\right), 4.0,4.1(4 \mathrm{H}$, 2 q, $\left.2 \mathrm{CH}_{2}\right), 6.3(1 \mathrm{H}, \mathrm{s}, \mathrm{CH}), 7.1-7.9\left(\mathrm{~m}, 10 \mathrm{H}, \mathrm{H}_{\text {arom }}\right.$ ), $8.3\left(1 \mathrm{H}, \mathrm{s}, \mathrm{NH}\right.$ exchangeable with $\left.\mathrm{D}_{2} \mathrm{O}\right) .-{ }^{13} \mathrm{C}$ NMR $\left(125.76 \mathrm{MHz}, \mathrm{CDCl}_{3}\right): \delta=14.7,14.8\left(2 \mathrm{CH}_{3}\right), 61.8(2$ $\left.\mathrm{CH}_{2}\right), 107.4,122.7(\mathrm{CH}=\mathrm{C}), 128.2-132.4(\mathrm{CH}$ aromatic $)$, 165.6, $168.4(2 \mathrm{C}=\mathrm{O})$. - MS (EI, $70 \mathrm{eV}): m / z(\%)=322$ (55) $[\mathrm{M}]^{+} .-\mathrm{C}_{20} \mathrm{H}_{22} \mathrm{~N}_{2} \mathrm{O}_{2}$ (322.17): calcd. C 71.51, H 6.88, $\mathrm{N}$ 8.69; found C 72.02, H 6.53, N 9.32.

\section{N-[(1-Dimethylcarbamoyl)-2-(4-(dimethylamino)phenyl)- vinyl]benzamide (16c)}

Product 16c was separated as colorless needles (diethyl ether), yield $90 \%$. M. p. $132-133^{\circ} \mathrm{C} .-\mathrm{IR}(\mathrm{KBr}): v=3360$ $(\mathrm{NH}), 1662,1650(2 \mathrm{C}=\mathrm{O}) \mathrm{cm}^{-1} .-{ }^{1} \mathrm{H}$ NMR $(500.14 \mathrm{MHz}$, $\left.\mathrm{CDCl}_{3}\right): \delta=3.0-3.2\left(12 \mathrm{H}, 2 \mathrm{~s}, \mathrm{~N}\left(\mathrm{CH}_{3}\right)_{2}\right), 6.0(1 \mathrm{H}, \mathrm{s}, \mathrm{CH})$, 6.6-7.8 (m, 9H, $\left.\mathrm{H}_{\text {arom }}\right), 8.5(1 \mathrm{H}, \mathrm{s}, \mathrm{NH}$ exchangeable with $\left.\mathrm{D}_{2} \mathrm{O}\right) .-{ }^{13} \mathrm{C}$ NMR $\left(125.76 \mathrm{MHz}, \mathrm{CDCl}_{3}\right): \delta=44.9-45.1$ $\left(2 \mathrm{~N}\left(\mathrm{CH}_{3}\right)_{2}\right), 117.0,127.1(\mathrm{CH}=\mathrm{C}), 131.0-136.9(\mathrm{CH}$ aromatic), 165.5, $168.1(2 \mathrm{C}=\mathrm{O})$. $-\mathrm{MS}(\mathrm{EI}, 70 \mathrm{eV}): m / z(\%)=$ 337 (50) $[\mathrm{M}]^{+} .-\mathrm{C}_{20} \mathrm{H}_{23} \mathrm{~N}_{3} \mathrm{O}_{2}$ (338.18): calcd. C 71.19, H 6.87, N 12.45; found C 71.80, H 6.44, N 12.02.

\section{$\mathrm{N}$-[(1-Diethylcarbamoyl)-2-(4-dimethylamino)phenyl)- vinyl]benzamide (16d)}

Product 16d was separated as colorless needles (ethyl acetate), yield $90 \%$. M. p. $232-233{ }^{\circ} \mathrm{C}$. $-\mathrm{IR}(\mathrm{KBr}): v=3354$ $(\mathrm{NH}), 1659,1650(2 \mathrm{C}=\mathrm{O}) \mathrm{cm}^{-1} .-{ }^{1} \mathrm{H}$ NMR $(500.14 \mathrm{MHz}$, $\left.\mathrm{CDCl}_{3}\right): \delta=0.8-1.1\left(6 \mathrm{H}, 2 \mathrm{t}, \mathrm{N}\left(\mathrm{CH}_{2} \mathrm{CH}_{3}\right)_{2}\right), 2.9(6 \mathrm{H}$, s, $\left.\mathrm{N}\left(\mathrm{CH}_{3}\right)_{2}\right), 4.1,4.3\left(4 \mathrm{H}, 2 \mathrm{q}, \mathrm{N}\left(\mathrm{CH}_{2} \mathrm{CH}_{3}\right)_{2}\right), 6.9(1 \mathrm{H}, \mathrm{s}$, $\mathrm{CH}), 7.1-7.8\left(\mathrm{~m}, 9 \mathrm{H}, \mathrm{H}_{\text {arom }}\right), 8.3(1 \mathrm{H}, \mathrm{s}, \mathrm{NH}$ exchangeable with $\left.\mathrm{D}_{2} \mathrm{O}\right) .-{ }^{13} \mathrm{C} \mathrm{NMR}\left(125.76 \mathrm{MHz}, \mathrm{CDCl}_{3}\right): \delta=$ $12.9\left(\mathrm{~N}\left(\mathrm{CH}_{2} \mathrm{CH}_{3}\right)_{2}\right), 40.1\left(\mathrm{~N}\left(\mathrm{CH}_{3}\right)_{2}\right), 61.2\left(\mathrm{~N}\left(\mathrm{CH}_{2} \mathrm{CH}_{3}\right)_{2}\right)$, 107.4, $122.7(\mathrm{CH}=\mathrm{C}), 128.2-148.4$ (aromatic $\mathrm{CH}), 163.6$, $168.4(2 \mathrm{C}=\mathrm{O})$. - MS (EI, $70 \mathrm{eV}): m / z(\%)=367(15)$ $[\mathrm{M}]^{+} .-\mathrm{C}_{22} \mathrm{H}_{27} \mathrm{~N}_{3} \mathrm{O}_{2}$ (367.21): Calcd. C 72.30, H 7.45, N 11.50; found C 71.89, H 7.40, N 12.01 .

\section{$N$-[(1-dimethylcarbamoyl)-2-(3,4,5-trimethoxyphenyl)- vinyl]benzamide (16e)}

Product 16e was separated as colorless needles, yield $75 \%$. - M.p. $150-152{ }^{\circ} \mathrm{C}$ (ethyl acetate). - IR (KBr): $v=3360(\mathrm{NH}), 1656,1650(2 \mathrm{C}=\mathrm{O}) \mathrm{cm}^{-1} \cdot-{ }^{1} \mathrm{H} \mathrm{NMR}$ 
$\left(500.14 \mathrm{MHz}, \mathrm{CDCl}_{3}\right): \delta=2.9-3.2\left(6 \mathrm{H}, 2 \mathrm{~s}, \mathrm{~N}\left(\mathrm{CH}_{2} \mathrm{CH}_{3}\right)_{2}\right.$, ), $3.8\left(9 \mathrm{H}, 2 \mathrm{~s},\left(3 \mathrm{OCH}_{3}\right), 6.0(1 \mathrm{H}, \mathrm{s}, \mathrm{CH}), 6.6-7.8(\mathrm{~m}\right.$, $\left.7 \mathrm{H}, \mathrm{H}_{\text {arom }}\right), 8.5\left(1 \mathrm{H}, \mathrm{s}, \mathrm{NH}\right.$ exchangeable with $\left.\mathrm{D}_{2} \mathrm{O}\right)$. ${ }^{13} \mathrm{C}$ NMR $\left(125.76 \mathrm{MHz}, \mathrm{CDCl}_{3}\right): \delta=37.2\left(\mathrm{~N}\left(\mathrm{CH}_{2} \mathrm{CH}_{3}\right)_{2}\right)$, 56.0, $60.5\left(3 \mathrm{OCH}_{3}\right), 107.4,127.1(\mathrm{CH}=\mathrm{C}), 128.2-132.4$ (CH aromatic), 165.6, $168.4(2 \mathrm{C}=\mathrm{O}) .-\mathrm{MS}(\mathrm{EI}, 70 \mathrm{eV})$ : $m / z(\%)=384(35)[\mathrm{M}]^{+} .-\mathrm{C}_{21} \mathrm{H}_{24} \mathrm{~N}_{2} \mathrm{O}_{5}$ (384.17): calcd. C 65.61, H 6.29, N 7.29; found C 66.01, H 6.27, N 7.83.

\section{N-[(1-Diethylcarbamoyl)-2-(3,4,5-trimethoxyphenyl)-} vinyl]benzamide (16f)

Product 16f was separated as colorless needles, yield $85 \%$. - M.p. $149-150{ }^{\circ} \mathrm{C}$ (cyclohexane). - IR $(\mathrm{KBr}): v=3368(\mathrm{NH}), 1660,1650(2 \mathrm{C}=\mathrm{O}) \mathrm{cm}^{-1}$. ${ }^{1} \mathrm{H}$ NMR (500.14 MHz, $\left.\mathrm{CDCl}_{3}\right): \delta=1.22-1.24(6 \mathrm{H}, 2 \mathrm{t}$, $\mathrm{N}\left(2 \mathrm{CH}_{2} \mathrm{CH}_{3}\right), 3.8-3.9\left(9 \mathrm{H}, 2 \mathrm{~s}, 3 \mathrm{OCH}_{3}\right), 3.92,3.95(4 \mathrm{H}$, $2 \mathrm{q}, \mathrm{N}\left(2 \mathrm{CH}_{2} \mathrm{CH}_{3}\right), 6.2(1 \mathrm{H}, \mathrm{s}, \mathrm{CH}), 6.6-8.3\left(\mathrm{~m}, 7 \mathrm{H}, \mathrm{H}_{\text {arom }}\right)$, $8.4\left(1 \mathrm{H}, \mathrm{s}, \mathrm{NH}\right.$ exchangeable with $\left.\mathrm{D}_{2} \mathrm{O}\right) .-{ }^{13} \mathrm{C}$ NMR

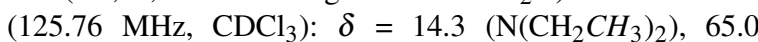
$\left(3 \mathrm{OCH}_{3}\right), 60.5\left(\mathrm{~N}\left(2 \mathrm{CH}_{2} \mathrm{CH}_{3}\right), 107.4,122.7(\mathrm{CH}=\mathrm{C})\right.$, 128.2-153.1 (aromatic CH), 165.3, $167.4(2 \mathrm{C}=\mathrm{O})$. - MS (EI, $70 \mathrm{eV}): m / z(\%)=412(45)[\mathrm{M}]^{+} .-\mathrm{C}_{23} \mathrm{H}_{28} \mathrm{~N}_{2} \mathrm{O}_{5}$ (412.2): calcd. C 66.97, H 6.84, N 6.79; found C 66.45, H 6.92, N 6.97.

\section{Pharmacological activity}

\section{Materials and methods}

Chemicals: All chemicals and reagents used in this study were of analytical grade and purchased from Sigma Chemical Co., St. Louis, Mo (USA).

Cell culture: MCF7 human breast cancer cells were maintained and grown in RPMI-1640 medium supplemented with $10 \%$ heat-inactivated fetal borine serum (Sigma Chemical Co., St. Louis, USA), penicillin and streptomycin at $37^{\circ} \mathrm{C}$ in humidified atmosphere containing $5 \% \mathrm{CO}_{2}$.

In vitro cytotoxicity assay: For in vitro short-term cytotoxicity evaluation of prepared compounds, MCF7 cells were placed at a concentration of $5 \times 10^{4}-10^{5}$ cells per well, in complete culture medium in 96 well flat-bottomed culture plates (Falcon) for $24 \mathrm{~h}$ to ensure total attachment. Then various concentrations of test compounds were added to the cells suspended in $0.10 \mathrm{~mL}$ of phosphate buffered saline (FBS) (0.20 M, pH 7.4). The control cells without the test compounds were also cultured, then the plate was incubated for $24 \mathrm{~h}$ at $40{ }^{\circ} \mathrm{C}$ and $72 \mathrm{~h}$ at $37{ }^{\circ} \mathrm{C}$, in a humidified $5 \% \mathrm{CO}_{2}$ atmosphere. Cell survival was evaluated at the end of the incubation period with the Sulphorhodamine-B (SRB) colorimetric assay according to Skehan et al. [24]. This test is based on the sensitivity of the human tumor cell lines to thymoquinone as determined by the SRB assay. SRB is a bright pink aminoxanthrene dye with two sulfonic groups. It is a protein stain that binds to the amino groups of intra- cellular proteins under mildly acidic conditions to provide a sensitive index of cellular protein content. After incubation, media were removed and $50 \mu \mathrm{L}$ of $0.4 \%$ SRB dissolved in $1 \%$ acetic acid solution was added and then washed 4 times with $1 \%$ acetic acid. The absorbance was determined photometrically at $564 \mathrm{~nm}$ with an ELISA microplate reader (Meter tech. $\Sigma 960$, USA).

Calculation: The percentage of cell survival was calculated as follows: Survival fraction = O.D. (treated cells) / O. D. (control cells) where (O. D.) is the optical density. The $\mathrm{IC}_{50}$ values are the concentrations of thymoquinone required to produce $50 \%$ inhibition of cell growth. The experiment was repeated 3 times for each cell line.

\section{Evaluation of antischistosomal activity of some compounds}

Materials: Adult worms of Schistosoma mansoni (Egyptian strain) are obtained by infecting Syrian golden hamsters (Mesocricetus auratus) by percutaneous infection of 350 cercariae / animal, freshly shed from infected Biomphalaria alexandrina snails [30]. The animal experiments were carried out according to the internationally valid guidelines in an institution coping with biological ethics (Theodor Bilharz Research Institute) [31]. Worms are obtained by portomesenteric perfusion, $45 \mathrm{~d}$ post infection using citrated saline (7.5 g sodium citrate $+8.5 \mathrm{~g}$ sodium chloride per liter).

The worms in a small sterilized sieve were washed three times with phosphate buffer $(\mathrm{pH}=7.4)$, then three times with a RPMI-1640 medium with L-glutamine containing antibiotics (300 $\mu \mathrm{g}$ Streptomycin, 300 units Penicillin and $160 \mu \mathrm{g}$ Gentamycin) $+20 \%$ foetal calf serum, inside a sterilization laminar flow. Then the worms were poured into a small petri dish. Compound samples were kept at $-20{ }^{\circ} \mathrm{C}$ in the dark.

The heterocyclic compounds were tested at a concentration of $10 \mu \mathrm{g} \mathrm{mL}^{-1}$ for in vitro bioactivity on viable Schistosoma mansoni mature worms in a culture medium (RPMI 1640). Three replicates were used for each compound and three pairs of worms, males and females equally represented, were placed in each vial containing the medium and the compound. The worms were considered dead when they did not show mobility for one minute.

The viability ratio of worms was determined by calculating the number of dead worms relative to the total number of worms. The results were compared with negative (DMSO) and positive (Praziquantel) controls. Praziquantel (PZQ) is the mainstay of schistosomiasis control programs worldwide.

\section{Acknowledgement}

We are grateful to the Cancer Biology Department, National Cancer Institute, Cairo University, for the pharmacological evaluation and Dr. F. Ramzy, Theodor Bilharz Research Institute, for antischistosomal activity evaluations. 
[1] O. Aleksiuk, D. Z. Gabriel, D. Kantoci, E. D. Murray, W. J. Wechter, D. Borchard, F. H. Ebetino, Phosphorus Sulfur and Silicon and The Related Elem. 1999, 147, $3-5$.

[2] a) F. H. Ebetino, S. M. Dansereau in Bisphosphonate on Bones (Eds.: O. Bijvoet, H. A. Fleisch, R. E. Canfield, G. Russell), Elsevier, Amsterdam, 1995, p. 139; b) F. H. Ebetino, M. D. Francis, M. J. Rogers, G. Russell, Rev. Contemp. Pharmacother. 1998, 9, 233-243.

[3] a) C. Dufau, G. Sturtz, Phosphorus Sulfur and Silicon and The Related Elem. 1992, 69, 93 - 102; b) C. Yuan, C. Li. Phosphorus Sulfur and Silicon and The Related Elem. 1992, 69, 75-81.

[4] A. Lesieur, H. Aichew, Eur. Patent 390: 673, 03, 1990; Chem. Abstr. 1991, 114, 143.

[5] K. Ando, N. Asai, Eur. Patent 385: 664, 05, 1990; Chem. Abstr. 1991, 114, 143.

[6] P. Descas, C. Jerry, Eur. Patent 392, 929, 17, 1990; Chem. Abstr. 1991, 114, 143.

[7] V. B. Doctorovich, E. M. Burgess, J. Lambropoulos, D. Ladnicer, D. V. Derveer, L. H. Zalkow, J. Med. Chem. 1994, 37, 710-712.

[8] E. R. Pereira, M. Sancelme, A. Voldoire, M. Prudhomme, Bio-Org. Med. Chem. Lett 1997,7,19, $2503-$ 2506.

[9] G. Viti, R. Nannicine, R. Ricci, V. Pestellini, L. Abelli, M. Furio, Eur. J. Med. Chem. 1994, 29, 401-406.

[10] L. S. Boulos, M. H. N. Arsanious, F.E. Ewies, Phosphorus Sulfur and Silicon and The Related Elem. 2009, 184, 275-290.

[11] L.S. Boulos, M.H.N. Arsanious, F.E. Ewies, R. Fatem, Z. Naturforsch., 2008, 63b, $1211-1218$.

[12] L.S. Boulos, M.H.N. Arsanious, E. M. A. Yakout, Monatsh. Chem. 2007, 138, 979-984.

[13] L.S. Boulos, E. M. A. Yakout, M.H. N. Arsanious, Phosphorus Sulfur and Silicon and The Related Elem. 2006, 181, 1615-1623.

[14] M. H. N. Arsanious, L. S. Boulos, Monatsh. Chem. 2006, 137, $1177-1184$.

[15] L.S. Boulos, N. K. El-Din, M. H. N. Arsanious, Phosphorus Sulfur and Silicon and The Related Elem. 2006, $181,1467-1475$.
[16] M. H. N. Arsanious, S.S. Magli, L.S. Boulos, Phosphorus Sulfur and Silicon and The Related Elem. 2010, $185,57-67$.

[17] B. C. Ranu, S. Banerjee, Org. Lett. 2005, 7, $3049-$ 3052.

[18] W. M. Abdou, N. A. S. Ganoub, Y. O. El-Khoshnie, Syn. Lett. 2003, 6, $785-790$.

[19] N. Nelson, R. B. Levy, J. Catal. 1979, 58, 485-491.

[20] C. G. Krespan, J. Am. Chem. Soc. 1961, 83, $3434-$ 3437.

[21] H. J. Bestmann, G. Schmid, D. Sandmeier, Angew. Chem. 1976, 88, 92 -93; Angew. Chem., Int. Ed. Engl. 1976, 15, $115-116$.

[22] Y. J. Surth, Nat. Rev. Cancer 2003, 3, 768 - 750.

[23] C.N. Borissow, C.L. Graham, R. T. Syvitski, T. R. Reid, J. Blay, D. L. Jakeman, ChemBioChem, 2007, 8, $1198-1203$.

[24] P. Skehan, R. Storeng, D. Scudiero, A. Monks, J. McMahon, D. Vistica, J.T. Warren, H. Bokesch, S. Kenney, M. R. Boyd, J. Natl. Cancer Inst. 1990, 82, $1107-1112$.

[25] F. A. Fornari, J. K. Randolph, J. C. Yalowich, M. K. Ritke, D. A. Gewirtz, Mol. Pharmacol. 1994, 45, 649656.

[26] N. F. Hidalgo, B. Almirante, A. Pahissa, Clinc. Infect. Dis. 2009, 48, 1166.

[27] N. G. Nessim, S. I. Hassan, S. William, H. el-Baz, Arznei-Forsch. Drug Res. 2000, 50, 11, 1129-1133.

[28] C. Cativiela, J. M. Fraile, J. J. Garcia, M. P. Lopez, J. A. Mayoral, E. Pires, Tetrahedron: Asymm. 1996, 7, $2391-2398$.

[29] G.S. Gruzdyev, The chemical protection of plants, MIR publisher, Moscow, 1983, pp. 79-84.

[30] R. W. Addor, J. A. Furch, D. G. Kuhn, US Patent 5030735, 1991; Chem. Abstr. 1991, 115, P183084r.

[31] Y.-S. Liang, J. I. Bruce, D. A. Boyd, Laboratory Cultivation of Schistosome Vector Snails and Maintenance of Schistosoma Life Cycles, Proceedings of the first Sino-American Symposium, Vol. 1, pp. 34-48. 